九州大学学術情報リポジトリ

Kyushu University Institutional Repository

\title{
A Sedimentological Study of the Lower Permian Sakamotozawa Formation
}

Mikami, Takahiko

Faculty of Science, Kyushu University : Visiting Research Associate | Department of Geology, Yamaguchi University

https://doi.org/10.5109/1543681

出版情報：九州大學理學部紀要：Series D, Geology. 19 (3)，pp.331-372, 1969-11-10. Faculty of Science, Kyushu University バージョン :

権利関係 : 


\title{
A Sedimentological Study of the Lower Permian Sakamotozawa Formation
}

\author{
By
}

Takahiko MIKAMI

\begin{abstract}
This paper contains a result of a sedimentological study of the Sakamotozawa Formation, the type sequence for the Lower Permian Sakamotozawa Series of Japan, giving precise descriptions of limestones and sandstones of the formation.

The Sakamotozawa Limestone is petrographically classified into twelve lithologic-types. The cyclic features of the limestone display a gradual change of depositional environments from a shallow sea of a restricted water (probably a lagoonal one), with an intermittent desiccation of water at time, to a slightly deepened somewhat off-shore sea. The cyclic pattern of the Sakamotozawa Limestone is of a reversed order as compared with that of a typical cyclic sequence from a transgressive phase to regressive one in the sediments on the stable shelf. The peculiar pattern of the cycle may be related to a mode of a provincial tectonic movement.

Sandstone belongs to arenite with a small amount of matrix, and is divided into four types. With regard to major framework constituents of sandstones a serial change is recognized twice in the entire sequence, one from basal to upper $\mathrm{Sa}$ and the other from Sc-Sd to the Kanokura. The rock fragments and heavy mineral assemblages of all the sandstone types indicate sources which were mainly composed of chert and shale on one hand and andesite and dacite on the other.

Concluding remarks are given on the sedimentary environments and the tectonic significance of the sediments. The sediments have not the characters of "molasses" and had not been derived from the backgrounds which were rapidly rising by the orogenic movement. They have the characters of the sediments deposited on the island shelf.
\end{abstract}

\section{Contents}

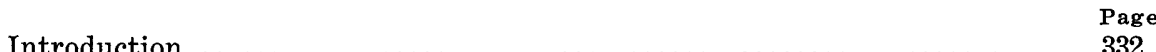

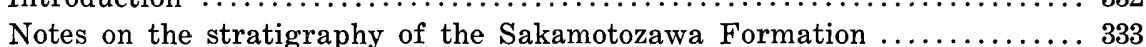

Sedimentology of the Sakamotozawa Limestone ................... 339

Sedimentology of the sandstones of the Sakamotoza and Kanokura

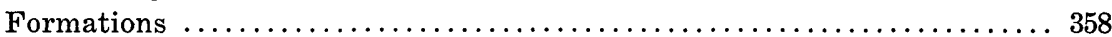

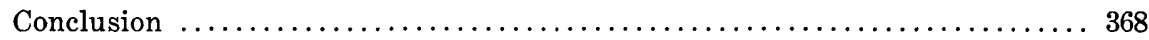

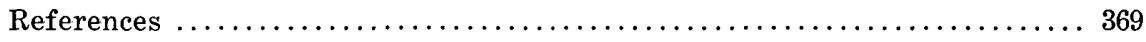

Manuscript received July 15, 1969.

Takahiko Mikami: Visiting Research Associate, Faculty of Science, Kyushu University, 1968; Present address: Department of Geology, Yamaguchi University, Yoshida, Yamaguchi, 753. 


\section{Introduction}

Since the pioneer work of ONUKI $(1937,1938)$, who established fundamentals in geology of the Kesen area of the south Kitakami mountains and named the Sakamotozawa Formation, stratigraphical study of the Sakamotozawa Formation has been carried on by many geologists, of whom ONUKI (1956) and MiNATo and his coworkers $(1954,1959)$ have made outstanding contributions. A fairly large number of fossils have also been described or listed to occur from the formation (HANZaWA, 1938, 1939; ToriYama, 1952; Morikawa, 1953; ENdo, 1951, 1952; NAKAMURA, 1959, 1960). From a standpoint of the geologic structure, KANO (1955) systematically measured the directions and plunges of linear structures of the strata, and gave some remarks on structural relations between the Sakamotozawa Formation and other units. Minato (1966) delivered his opinion on the palaeotectonic history of the Palaeozoic time, summarizing the results of his investigations on the stratigraphy, palaeontology and geological structure of the Palaeozoic sediments in the Kesen area.

As a result of geological studies by a number of persons, an outline of the lithostratigraphy, as well as the approximate geological age, of the formation has been made clear. However, there has been no attempt of petrographical and sedimentological studies of the formation, which are indispensable for the precise discussion of the tectonic history.

The writer has been engaged in biostratigraphical and sedimentological studies of the Sakamotozawa Formation of the type area and adjoining Nagaiwa area since 1962. The results of his research on the stratigraphic sequence, zonal succession, and general sedimentary features of the formation, have already been published in parts (MIKami, 1965; Kanmera and Mikami, 1965a, 1965b). The purpose of the present paper is to describe the petrographical and sedimentological characters of limestones and sandstones and to give some comments on the mode of sedimentation and, furthermore, on the relation between sedimentation and tectonics in the Lower Permian Epoch in the southern Kitakami region.

\section{Acknowledgements}

This study was undertaken at the suggestion of Professor Tatsuro Matsuмото of Kyushu University when the writer was a graduate student of the same university. It was continued since he removed from Kyushu University to Yamaguchi University and completed during the tenure of his stay at Kyushu University as a Visiting Research Associate, 1968. The writer wishes to express his sincere thanks to Professor Tatsuro MATsumoto who has given valuable advice in many respects and critically read the manuscript. Special thanks are due to Assist. Professor Kametoshi Kanmera for his collaboration in the stratigraphical and palaeontological study and for valuable advice on the sedimentological study of limestones and to Dr. Hakuyu OKADA for his kind advice on the sedimentological study of sandstones. Assist. Professor Kanmera and Dr. OKADA also critically read the first draft of this paper. Thanks for field work 
are due to Professor Matsumoto, Assist. Professor Kanmera and Dr. OKada. The writer is indebted to Professor Ryuzo TORIYAMA for his privilage for free use of his private library in the study of fusuline, and to Dr. Itaru HaYamr for his helpful discussions.

The writer was assisted by Dr. Jonosuke OBARA in the study of heavy minerals, Mr. Kiyoshi IsHIBASHI in the petrographical study of sandstone and Mr. Masaharu OzAKI in the determination of minerals of the red beds.

Finally, the writer wishes to express his particular thanks to Professor Hisashi KUSUmI of Hiroshima University who has kindly continued encouragement for his study, to Professor Eitaro TAKAHASHI of Yamaguchi University who has affored him every facility for this study since the writer removed from Kyushu University to Yamaguchi University.

Financial aids for this study were partly granted by the Ministry of Education, by the Ikueikai Scholarship, and by a Scholarship Fund of Professor Tatsuro Matsumoto.

\section{Notes on the stratigraphy of the Sakamotozawa Formation}

The Sakamotozawa Formation, the type sequence for the Lower Permian Sakamotozawa Series of Japan, rests on the lower and middle Upper Carboniferous Nagaiwa Formation with a remarkable unconformity as clarified by Minato (1941) and others, and is conformably overlain by the Middle Permian

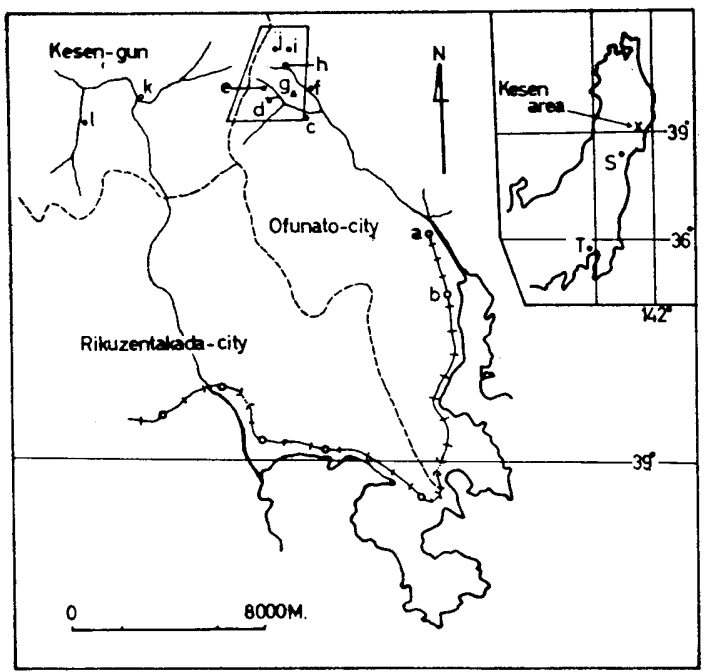

Fig. 1. Map showing the studied area with an index map of northeast Japan.

T. Tokyo; S. Sendai; a. Sakari-station; b. Ofunatostation; c. Sakamotozawa; d. Yubanosawa; e. Shiratorizawa; f. Tashiroyashiki; g. Tashiroyama; h. Nagaiwa; i. Higashiyama quarry of the Nagaiwa mine; j. Nishiyama quarry of the Nagaiwa mine; k. Setamai-machi; 1. Kacchizawa. 


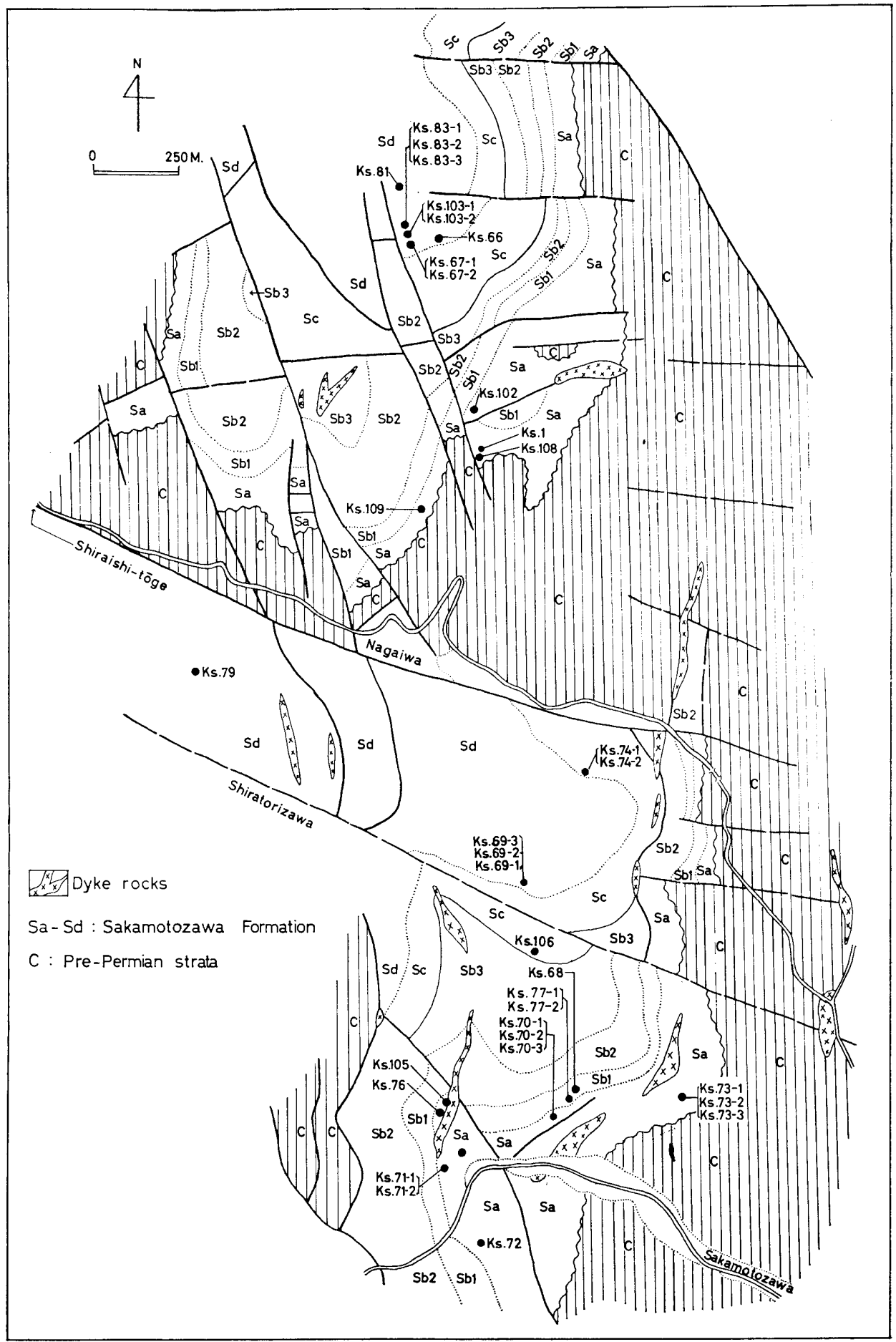

Fig. 2. Geological map of the Sakamotozawa-Nagaiwa area, showing the localities of the sandstone samples. 
Kanokura Formation. It is about $270 \mathrm{~m}$. thick in the type area (SakamotozawaNagaiwa area) and is lithologically divided into two subformations separated by a disconformity (Mikami, 1965; KANMERA and Mikami, 1965a).

Fig. 3 shows a generalized stratigraphic section compiled from the sections at Shiratorizawa, Tashiroyama and the Nagaiwa mine of the Onoda Cement Co. Ltd., where almost continuous exposures are seen. The distribution of the subdivided units is shown in the accompanying geological map (Fig. 2).

The following is a summarized description of the stratigraphy of the Sakamotozawa Formation in ascending order.

\section{A. Lower Subformation}

1. Member Sa (35-55 m. thick): This basal member consists primarily of conglomerate, sandstone and black shale*.

The lower part is made up of a thick bed of conglomerate which has been called the Sakamotozawa conglomerate (MINATo, 1941, 1942; ONUKI, 1956; YAMADA, 1959). It is moderately well sorted and contains subangular to subrounded pebbles and granules mainly of shale and chert and subordinately of porphyrite, but no pebbles of granitic rocks are found. Thin beds of lithic sandstone, which is mainly composed of grains of chert and shale, are intercalated at a few horizons.

The succeeding middle part is made up primarily of medium- to coarse-, and subordinately of fine-grained, light greenish grey, fairly massive feldspathic arenite. A few lenticular beds of conglomerate and black shale are locally interbedded.

Some beds of silty to fine-grained sandstone are locally fossiliferous with remains of molluscs, brachiopods and corals. Another fine-grained sandstone bed is rich in fusuline remains.

The upper part of this member consists mainly of massive black mudstone with some thin beds of fine- to medium-grained, brachiopod-bearing calcareous sandstone at the top.

2. Member Sb1 (30-35 m. thick): This member is best exposed in Sakamotozawa and at the Nishiyama quarry of the Nagaiwa mine. The lower half of the member is made up of alternating beds of algal biomicrudite and black shale. The algal bed is thin-bedded (mostly 10 to $30 \mathrm{~cm}$., rarely up to $50 \mathrm{~cm}$. thick), dark grey and characterized by nodular to biscuit-shaped stromatolites, that is, oncolites (see Pl.5, Figs. 1-3). The black shale is thin-bedded and commonly contains crinoid fragments. The upper part of this member consists mainly of thick-bedded $(50 \mathrm{~cm}$. to $1 \mathrm{~m}$. thick), dark-grey biomicrudite, containing a large number of fragmentary oncolites. Thin beds of crinoidal biomicrite and biosparite are occasionally intercalated at some horizons. Fusulines occur in abundance at several horizons as shown in Fig. 4.

3. Member $\mathrm{Sb2}(55-80 \mathrm{~m}$. thick): This member is composed mainly of bedded or partly massive, grey to light grey biomicrudite or biomicrite, showing four cycles of sedimentation (see Chapter IIIB).

\footnotetext{
* Shale and mudstone of the Sakamotozawa Formation are all converted to slate.
} 


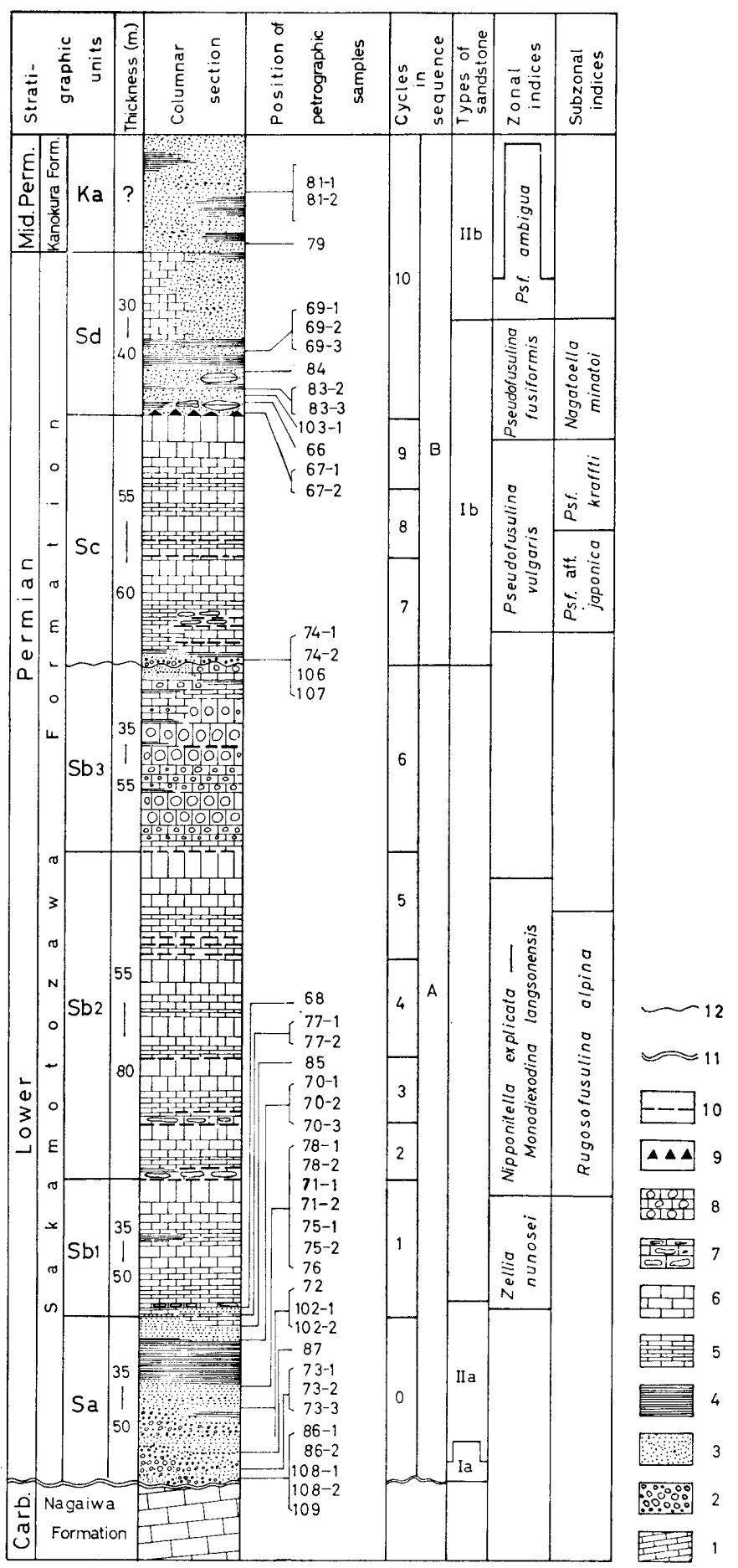

Fig. 3. Generalized stratigraphic section of the Sakamotozawa Formation of the Sakamotozawa-Nagaiwa area, showing the stratigraphic position of the sandstone samples.

1. Nagaiwa Formation; 2. conglomerate; 3 . sandstone; 4. shale; 5. thinbedded limestone; 6. thick-bedded limestone; 7. oncolitic limestone; 8. crinoidal limestone; 9 . iron beds; 10 . red limy clay; 11. unconformity; 12. disconformity. 
Brachiopods occur abundantly in thin-bedded dark-grey biomicrite with reddish-purple limy clay partings. Fusulines are found at several horizons and their mode of occurrence is mentioned in Chapter IIIB.

Member $\mathrm{Sb2}$ in the Sakamotozawa area also shows cyclic sedimentation comparable to that in the Nagaiwa area.

4. Member Sb3 (35-55 m. thick): This consists mostly of thin-bedded to massive, grey to light grey crinoidal biopseudosparudite, but in the lower and upper parts thin beds (mostly $30-50 \mathrm{~cm}$.) of shale are intercalated in the Nagaiwa area. Organic constituents are almost exclusively crinoid columnals and plates that are generally 3 to $5 \mathrm{~cm}$. and sometimes as long as $10 \mathrm{~cm}$. They are very poorly sorted at the Higashiyama quarry of the Nagaiwa mine where this member is best exposed. In the Sakamotozawa area, however, they become smaller grains (mostly $1 \mathrm{~cm}$.) and better sorted. The upper part of this member exposed in the Sakamotozawa area, besides lithic sandstone and black shale, comprises conglomeratic sandstone containing predominant pebbles of various sedimentary rocks, such as chert, shale and limestone.

Fusulines are occasionally found in the lower part at the Higashiyama quarry of the Nagaiwa mine and Shiratorizawa, but most of them are too fragmentary and too much deformed for the identification of species.

\section{B. Upper Subformation}

This overlies unconformably the lower subformation and is divided into two members, Sc and Sd.

1. Member Sc $(55-60 \mathrm{~m}$. thick): This is best exposed in the Higashiyama quarry of the Nagaiwa mine. Its basal part begins with conglomerate containing very angular granules and pebbles of limestone. The thickness of this conglomerate varies laterally, but does not exceed $1 \mathrm{~m}$. The succeeding unit is a sequence of bedded $(20-50 \mathrm{~cm}$. thick), grey biomicrite, containing gastropods and fusulines. At the top of this unit the biomicrite is intercalated by a reddish-purple limy clay bed $(10-20 \mathrm{~cm}$.).

The middle part of this member consists of thin-bedded $(5-15 \mathrm{~cm}$.), black biomicrudite in the main part and three thick beds (each $1.5 \mathrm{~m}$.) of dark-grey biomicrudite, containing biscuit-shaped algal nodules, in the upper portion. The middle part is the most fossiliferous in the Sakamotozawa Formation. Its thinbedded biomicrudite is crowed with well-preserved dasycladacea algae (mainly Mizzia), gastropods, simple corals, tabulate corals (mainly Michelinia), fusulines and small foraminifers.

The upper part of this member consists of bedded (10 to $20 \mathrm{~cm}$. thick), darkgrey algal biomicrite with some reddish-purple limy clay partings in the lower portion, bedded (20 to $40 \mathrm{~cm}$. thick), dark-grey biomicrite in the middle, and thick bedded ( 1 to $1.5 \mathrm{~m}$. thick), grey biomicrite and thin-bedded biomicrite in the upper. This part is less fossiliferous and better sorted than the lower and middle parts of this member.

In the Sakamotozawa area, this member is composed of bedded (5 to $30 \mathrm{~cm}$. thick), black biomicrudite in the main part and alternating black shale and sand- 
stone (about $10 \mathrm{~m}$.) in the upper part.

2. Member Sd (30-40 m. thick): As this member in poorly exposed in the surveyed area, its lithology and succession cannot be known so precisely as in underlying members. As far as the available data are concerned, it is composed mainly of alternating shale and fine- to medium-grained sandstone. Some lenticular bodies or thin beds of limestone are intercalated in the lower part. The lenticular body of limestone, 2-5 m. in length and 1-2 m. in thickness, is mostly biomicrudite with many fusulines and is partly conglomeratic with fine-grained terrigenous substance in the matrix. The thin-bedded limestone which alternates with black shale and calcareous sandstone is also mainly biosparudite with terrigenous sand. The sandstone in the upper part of the member is thin-bedded and intercalated with shale in the Nagaiwa area, but is more or less argillaceous and thick bedded in the Sakamotozawa area.

In the fine- to medium-grained lithic arenites in the basal part of this member occur lenticular to nodular bodies, each 5 to $50 \mathrm{~cm}$. thick, of ferruginous rock.

\section{Disconformity between the Lower and Upper Subformation}

Member Sb3 and Member Sc are separated by a distinct disconformity, which is persistent in the surveyed area. The disconformity is shown not only on exposures but also by clear difference between two members in lithology and faunal assemblage. It corresponds to the boundary between the major sedimentary cycles $\mathrm{A}$ and $\mathrm{B}$ mentioned in Chapter IIIB, and indicates the uplift accompanied by slight folding and erosion.

This disconformity is best exposed at the Higashiyama quarry of Nagaiwa mine where the following details are recognized.

Structural relation between Member Sb3 and Member Sc: At the Higashiyama quarry the basal limestone-conglomerate (about $1 \mathrm{~m}$.) of Member Sc is horizontally followed over $30 \mathrm{~m}$. This conglomerate is mainly composed of granule- to pebble-size limestone and rests with an eroded surface on Member Sb3, showing a crosscut relation of 20-30 degrees in strike and about 10 degrees in dip. As the limestone-conglomerate commonly contains detrital quartz sand and silt in the matrix, it exhibits light brownish grey in colour. On the other hand the limestone of Member Sb3 is white to light grey. Accordingly, the boundary between the two members is clearly shown.

Another exposure of similar limestone-conglomerate is seen in a trench cutting the eastern slope about $100 \mathrm{~m}$. north of the Nishiyama quarry. In the Tashiroyama the basal part of Member Sc is composed of conglomerate containing pebbles and granules of quartz, chert, shale and limestone. In all of these exposures the unconformity is recognized below the Pseudofusulina vulgaris zone.

Lithology of limestone and faunal assemblage: Member Sb3 consists of white to light grey, massive or thick-bedded limestone. Its constituent is almost exclusively crinoid fragments with a micritic lime-mud matrix, except for a small amount of fusulines occurring in its lower part. On the other hand, the lower part of Member Sc is commonly composed of thick-bedded, dark-grey micritic 
limestone with a small amount of organic debris, in which crinoid fragments are extremely rare. The middle and upper parts of Member Sc consist of black to dark-grey, thin- to thick-bedded biomicrite or biomicrudite. This limestone contains abundantly remains of fusulines, gastropods, pelecypods, simple corals, tabulate corals and algae throughout the sequence. These differences in lithology and organic contents indicate the change of depositional environment.

The change of fusuline assemblage at the disconformity between Member Sc and the Lower Subformation is very clear as mentioned in the previous paper (KANMERA and Mikami, 1965a, p. 268, fig. 1). Most species of the Lower Subformation do not range up to Member Sc, while several large species of Pseudofusulina appear in Sc and Sd. Only a few species, such as Minojapanella elongata, Nankinella kawadai, and Pseudoschwagerina (Robustoschwagerina) schellwieni, extend from $\mathrm{Sb}$ (or $\mathrm{Sa}$ ) to the Upper Subformation. Most species of Pseudoschwagerina and Paraschwagerina (s. 1.) are confined to the Lower Subformation.

As is mentioned in the succeeding paragraph (Fig. 3) the zone of Nipponitella explicata-Monodiexodina langsonensis is recognized in $\mathrm{Sb}$, while that of Pseudofusulina vulgaris (s. 1.) in Sc. To sum up the disconformity bears important significance to the stratigraphic division of the Lower Permian in the south Kitakami region.

\section{Correlattion and geological age of the Sakamotozawa Formation}

The zonation of the type Sakamotozawa Formation, with necessary systematic description of the fusulines, has already been given precisely (KANMERA and Mikami, 1965b). To cite from it the Sakamotozawa Formation is defined by successive five zones as shown in Fig. 3. In a major scheme the zone of Zellia nunosei and that of Monodiexodina langsonensis-Nipponitella explicata of the Lower Subformation may be grouped as the stage of Pseudoschwagerina, while the zone of Pseudofusulina vulgaris (s. 1.), that of $P$. fusiformis and that of $P$. ambigua of the Upper Subformation may be referred to the stage of Pseudofusulina. The zonal indices and the species assemblage of the five zones indicate that the Sakamotozawa Formation is correlated as a whole with the Triticites simplex zone to $P$. ambigua zone in the sequence of calcareous sediments of southwest Japan. The age is as a whole Early Permian in the tripartite scheme of the period.

\section{Sedimentology of the Sakamotozawa Limestone}

\section{A. Petrographic descriptions}

1. Classification and nomenclature of limestone

The writer would not attempt to give a historical review on the studies of the carbonate sediments, since critical comments have recently been given by HAM and PrAY (1962) and CHILINGAR et al. (1967). The following remarks may serve to illustrate the carbonate classification and terminology used in this paper.

In the up-to-date classification of carbonate rocks compositional elements and 
textural properties are generally selected as the fundamental parameters. The former in the common usage is the constituents which are expressed according to the kind of grains (fossils, oöids, pellets and limeclasts) and the mineralogical characters of the matrix (sparry calcite, micrite and dolomite). The latter involves the textural maturity (sorting and roundness) and grain size. The classificaion and nomenclature of the carbonate rocks are, however, more complicated than those of the terrigenous rocks, because the carbonate rocks not only include inherent properties, which are produced by interbasinal or in situ physicochemical processes and organic or biochemical activities, but also are often subject to extensive syngenetic, diagenetic and epigenetic alterations.

For the purely descriptive purpose the writer, adapting Folk's scheme (1959, 1962) with some modification, designates the following properties as classification parameters. A. Constituents (1. limeclasts, 2. fossils, 3. oöids, 4. pellets, 5. mixed bioclasts, 6. biolithites, 7. terrigenous material), B. Matrix (8. sparry calcite and/or "pseudosparite", 9. micrite), C. Grain size* (rudite, arenite and lutite). The term of a rock type is expressed by the combination of the predominant constituents, the kind of the matrix and the grain size, such as fusuline biomicrudite, crinoidal biosparite and algal pellet biomicrite. If the rock contains more than 10 per cent of dolomite or certain kinds of terrigenous material, the prefix "dolomitic", "quartz", "feldspar" and "silty" is added to the head of each rockname such as dolomitic fusuline biosparrudite or quartz crinoid biosparite. If the originally micritic matrix is recrystallized to sparry calcite, the term "pseudosparite" is used. Furthermore, if a limestone consists predominantly of three or more kinds of organic debris, each of which exceeds 20 per cent, the term "mixed bioclasts" is used. Chemical composition, textural fabric and diagenetic modifications which are very important factors for interpretation of depositional environments and paragenesis of the carbonate sediments are excluded from the parameters of the classification. Syngenetic to epigenetic features are, however, discussed to some extent in the description of each rock-types.

\section{Descriptions of the Sakamotozawa Limestone}

About 600 samples have been collected from various stratigraphic levels of the Sakamotozawa Limestone. They have been microscopically examined through thin-sections. The limestone is as a whole composed of fragmentary and nonfragmentary skeletal grains and is petrographically classified into twelve lithologic-types as follows:

1. oncolite biopseudosparrudite

2. algal pellet biomicrite

3. algal biomicrite

4. algal biomicrudite

5. fusuline biomicrudite

6. gastropod biomicrudite

7. feldspar crinoid biomicrudite

8. algal biosparite

\footnotetext{
* Grain size scale is defined in accordance with PeтtiJohn's (1957) scheme as follows:
} rudite $=2 \mathrm{~mm}$. over, arenite $=2$ to $0.062 \mathrm{~mm}$., lutite $<0.062 \mathrm{~mm}$. 
9. algal biosparrudite

10. fusuline biosparrudite

11. algal oöid biosparrudite

12. crinoidal biomicrudite

Oncolite biopseudosparrudite

(ex. Pl. 47, Fig. 3; Pl. 50, Fig. 3)

This limestone consists mainly of stromatolitic algal nodules called oncolite. This type of algal bodies has been variously called by authors, such as "algal oncolite", "algal ball", "algal nodule", "algal biscuit" and "algal stromatolite". The oncolite has recently been redefined by WoLF (1965a) as "unattached, i.e., allochthonous, components that have been either encrusted, circumcrusted or concentrically laminated by algal layer". In the present paper, however, oncolite is used according to the original definition of Young (1935, quoted in GiNsBURG, 1960) for unattached form of laminated algal stromatolites as a descriptive term. The small, spherical to subspherical bodies composed of thin algal layers or filaments completely encrusting a bioclastic or lithic fragment are not included in the oncolite. They are referred to "algal oöid".

These oncolites are elongate ellipsoidal or spherical in shape and relatively smooth on the surface, ranging mostly from 1 to $4 \mathrm{~cm}$. in longer diameter and from 0.5 to $1 \mathrm{~cm}$. in shorter diameter (i.e. thickness). Their internal and surface structures show that they were not abraded during and after their growth. They are arranged with a longer axis parallel to the bedding plane. They commonly have a shelly or other organic detrital core, but some of them have a nucleus of a terrigenous sand grain or a lithic fragment. In general, flattened ellipsoidal oncolites have a subcylindrical core, but spherical ones have a more rounded spherical core.

Individual oncolite is made up of alternating layers of grey cryptocrystalline calcite and darker ones, which surround a core. Each of the alternating layers ranges mostly from 0.2 to $1 \mathrm{~mm}$. (rarely over $1.5 \mathrm{~mm}$.) in thickness. These layers are in general concentrically stacked, but sometimes are thicker to the top side than to the bottom side of a stratum. This feature is useful to the top and bottom determination of a stratum as already noticed by CLoud (1942, p. 373). Secondary growths of minute quartz crystals, mostly between 0.01 and $0.03 \mathrm{~mm}$. in size, are recognized in the dark-grey or black layers, but are few in the greyish ones. In the dark-grey layers silty to finer-grained feldspar, quartz and other detrital grains are sometimes contained. These features well indicate the formation mechanism of laminated algal layers which grow by the alternating adhesion of fine-grained sediments on an algal filament as already mentioned by LOGAN, REZAK and GINSBURG (1964) and BATHURST (1967).

The matrix of this limestone is originally a micritic lime-mud, but its larger part is altered to fine-grained mosaic sparry calcite (pseudosparite). Finegrained (commonly $0.4 \mathrm{~mm}$.) detrial quartz, feldspar and rock fragments are contained in some parts. 
The term "stromatolites" has been referred not only to rocks with laminated algal bodies but also to rocks with other organic or inorganic laminated structures, since KALKOWSKI (1908, quoted in LoGAN et al., 1964, p. 68) originally defined. Recently the morphology and genesis of recent algal stromatolites have been intensively studied and the environmental conditions in which they are formed have become very clear.

LOGAN et al. (1964) gave a classification of algal stromatolites and some information about the environmental conditions of their growths. They subdivided oncolitic stromatolites of the "spheroidal structure" (SS) into three modes: inverted, stacked hemispheroids (SS-I), randomly stacked hemispheroids (SS-R) and concentrically stacked spheroids (SS-C). They stated that the prime requisite for the growth of SS type of stromatolites is movement of the stromatolitic body, and considered that the difference of the external and internal structure among the tree types (SS-I, SS-R, SS-C) is controlled by the degree and mode of agitation of water. They concluded that the SS-I type of stromatolites is formed in the shallow waters which are not greatly agitated, the SS-C type with concentric layers indicates the condition of continual motion of water and the SS-R type indicates periodical agitation. Other described examples of recent oncolite growths are those in the mouth of the River Murray in the Victorian border, South Australia (Mawson, 1929) and in the Florida Bay (GinsBurG*, 1955, 1956, 1960). These and some other studies (BATHURST, 1967; MCMASTER et al., 1966) clarified the environmental condition of oncolite formation and the relationship of it to the external and internal structures of oncolites. It is generally recognized that oncolitic algae are predominantly formed in the shallow waters such as those on the submerged shoals, the intertidal zone and coastal mud flats of lagoons which are periodically exposed and flooded.

Oncolites of the Sakamotozawa Limestone are composed of the concentrically stacked layers or the slightly crenulated layers. The internal structure of these oncolites resembles that of SS-C type of LoGAN et al. (1964), but the external form (an elongate ellipsoid) is closely similar to that of SS-I type. Most of the nuclei are perfectly enclosed by concentrically stacked alternating layers and the oncolites were undoubtedly formed on free-grains either of bioclasts or lithic fragments which were on the bottom. The external form is concordant with the shape of nuclei as already mentioned. There are no spheroidal algal bodies which have an elongate core as far as the writer has observed. These features suggest that the nuclei and algal bodies were gently rolling in water at right angles with their longer diameter by the wave. The wave action must have been sufficiently continuous to keep oncolitic bodies spherical but not so strong as to destroy them.

Ancient stromatolitic algal nodules have been reported by GURICH (1906, quoted by GinsburG, 1960) and JoHnson (1964) from the Lower Permian of Kansas and GEORge (1960) from the Lower Carboniferous of County Wexford, eastern Ireland. In Japan, KoNISHI (1959) reported algal stromatolites of the oncolitic type from the Permian Nabeyama Limestone at Kuzu. The algal lime-

* Ginsburg $(1960$, p. 29, table 1) reported that oncolitic algae occur at the depth of $15 \mathrm{~cm} .-1.4 \mathrm{~m}$. in the shallow bay or intertidal zone in Florida Bay. 
stone described by GEORGE (1960) is very similar in shape to that of the Sakamotozawa Limestone, although the algal remains are those of Codiaceae. He $(1960$, p. 356) considered that these algae were formed in a lagoonal shallow sea of intertidal condition with intermittent desiccation. Recent stromatolites described by BLACK, M. (1933, quoted by GinsBurg, 1960) occur on the mud flats which show evidence of periodic desiccation and erosion, e.g. mud cracks and desiccation breccias. Ginsburg $(1960$, p. 27) also stated that similar features are commonly recognized in some ancient attached stromatolite limestones.

The oncolite biopseudosparrudite of the Sakamotozawa Limestone are characteristically followed by a thin bed of reddish-purple limy clay as already described in a previous paper (KANMERA and MIKAMI, 1965a). The bed shows evidence of penecontemporaneous desiccation, which suggests a very shallow condition of oncolite sediments. To sum up, it can be concluded that oncolite biopseudosparrudite of the Sakamotozawa Limestone was formed in the intertidal zone of a kind of lagoon where gentle wave was prevailing.

\section{Algal pellet biomicrite}

(ex. Pl. 46, Fig. 3)

This is a moderately well-sorted limestone which consists mainly of fine- to medium-grained (mostly from 0.1 to $0.5 \mathrm{~mm}$. in size) detritus and subordinately of debris of crinoids and shells of uncertain affiliation and some small foraminifers. Monodiexodina (Ferganites) langsonensis occurs in this limestone. Subangular to subrounded detrital quartz grains are also contained. The detritus are commonly grumous, subangular to rounded, and consist of microcrystalline calcite. They are sometimes encrusted by lighter layers of microcrystalline calcite which show a texture similar to that of algae-encrusted body. This type of pellet has been called "algal pellet" and distinguished from fecal pellets by WoLF (1965d). He considered that algal pellets could be produced by the extreme abrasion of the ancient and/or penecontemporaneous algal bodies.

Algal pellets are also almost always contained in algal limestones such as oncolite biopseudosparrudite and algal oöid biosparrudite as accessory constituents. But algal pellet biomicrudite, which characteristically occurs in the middle to upper part of cyclic units 1-3, is no longer with the oncolitic algal nodules. In general, algal pellets increase in volume as the stratigraphic sequence of a cycle is followed upwards, and vice versa the oncolite and dasycladaceae algae.

Although associated organic fragments are relatively well-rounded and moderately well-sorted, the matrix consists of lime-silt which has been frequently recrystallized to fine-grained sparry calcite.

Algal biomicrite

(ex. Pl. 46, Figs. 4, 5; Pl. 47, Figs. 5, 6)

This limestone consists mainly of micritic lime-mud and -silt, and fine- to medium-grained debris of dasycladacean algae and crinoid with some algal pellets. 
The micritic lime-mud is composed of dense microcrystalline calcite. WoLF (1965b) discriminated two principal types of micrite*, orthomicrite formed by primary sedimentary processes and pseudo-micrite formed by disintegration of large calcium carbonate grains. An exact discrimination of the two types may be difficult. The abundance of the fine-grained debris of dasycladacean algae suggests that the micrite under consideration may have been derived from mechanical disintegration of algal debris.

The algal biomicrite, together with algal biomicrudite, is the main component of the upper part of each cycle in the Sakamotozawa Limestone.

\section{Algal biomicrudite}

(ex. Pl. 47, Fig. 1; Pl. 48, Fig. 5; Pl. 49, Figs. 1-4)

There are two types in this limestone, dasycladacean algal biomicrudite and fragmentary algal biomicrudite. The former consists of relatively well-preserved dasycladacean and codiacean algae, with some algal debris, simple corals and fragmentary oncolites. The constituents range mostly from 2 to $4 \mathrm{~mm}$., and rarely attain $6 \mathrm{~mm}$. Oncolitic algal fragments sometimes include rhombohedral quartz. The quartz crystals were probably formed by the grain-growth of detrital quartz grains which adhered on the algal layers in process of their formation.

This limestone is very poorly-sorted, and the contained organic constituents do not seem to have been washed by current action. Some organic debris are encrusted by thin algal layers (ex. Pl. 50, Fig. 1), and their marginal part is commonly destroyed by algal corrosion.

A biomicrudite of the middle part of the cyclic unit 8 which is composed of fine-grained (mostly from 0.02 to $0.15 \mathrm{~mm}$.) pseudosparite abundantly contains ghosts of Mizzia velevitana (from 0.5 to $1.0 \mathrm{~mm}$. in size). Thalli of Mizzia velevitana are recrystallized to larger crystals than the matrix.

The matrix of algal biomicrudite consists of a relatively homogeneous lime mud. It is dark-grey and lacks transparency. Probably it is derived mainly from algal-slime.

This type of limestone is predominant in the middle part of the cyclic units 1 (ex. Pl. 50, Fig. 1), 2, 3, 4 (ex. Pl. 47, Fig. 3) and 8 (ex. Pl. 47, Fig. 1; Pl. 50, Fig. 2).

The latter (ex. Pl.47, Fig. 2) is composed of poorly rounded and poorly sorted debris of oncolite, codiacean and dasycladacean algae and crinoids. The oncolitic fragments (pseudostromata) are the most common component of this limestone. These constituents may have been formed by the mechanical disintegration of the algal growths.

The matrix is composed of a dark-grey micritic lime-mud and fine-grained algal debris, some of which can be called "algal pellets".

This limestone predominantly occurs in the upper part of every cyclic sequence, except in the sixth.

\footnotetext{
* "Algal dust" by Wood (1941) is synonymous to micrite. CARozzi (1960) has made clear optical character of algal dust.
} 


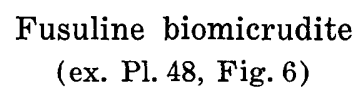

This type of limestone consists of abundant fusuline tests with a lime-silt and -mud matrix, and it can be subdivided into two types with respect to the texture and original character of the matrix.

The first type of the fusuline biomicrudite is characterized by a simple assemblage of contained fusulines which are few in species but very abundant in individuals and has a black to dark-grey, lime-silt and lime-mud matrix. The contained fusulines are Pseudofusulina vulgaris, $P$. fusiformis, $P$. aff. japonica, Pseudoschwagerina (Robustoschwagerina) schellwieni and Nipponitella explicata. The matrix consists of some fine-grained, poorly-sorted algal debris and indeterminable ones. Besides it contains intermixed silty and clayey minerals which are stained to light brown colour under the microscope, and some opaque minerals (ranging mostly from 0.05 to $0.1 \mathrm{~mm}$.). This feature is most typically seen in the Nipponitella biomicrudite. The lime-mud seems to have originated mainly from algal dust.

The texture of this limestone indicates a quiet environment of deposition. This is also supported by the presence of very well-preserved shells of Nipponitella which have a flaring uncoiled outer volution. The other fusuline species mentioned above are also well-preserved.

This limestone occurs in the middle part of cyclic units $2,3,4$ and 8.

The second type of fusuline biomicrudite has a better sorted matrix than that of the first type, and contains Pseudoschwagerina (Zellia) nunosei, Quasifusulina longissima, Monodiexodina (Ferganites) langsonensis and Rugosofusulina alpina. The matrix consists of lime-mud and poorly-rounded debris of dasycladacean and codiacean algae and oncolites. Amount and size of these debris vary remarkably from a specimen to another. Open spaces of various shape and size are frequently seen in this biomicrudite. They are filled up by mosaic sparry calcite, which is considered to be of diagenetic origin.

The matrix of this type of limestone seems to have originated from so-called "algal grain" with a small amount of algal dust.

This limestone occurs mainly in the lower to middle part of cyclic units $1,2,3$ and 4 .

Gastropod biomicrudite

(ex. Pl. 47, Fig. 2; Pl. 49, Fig. 3)

Well-preserved gastropods are the main framework constituents of this limestone. Fragments of brachiopod shells, bryozoas and small foraminifers are also contained as accessory components. The matrix is composed of a mixture of dark-grey micritic lime-mud and fine-grained organic debris of varied shape. A majority of the debris consists of dark-grey or light-grey, grumous microcrystalline calcite, and the remaining part retains the dasycladacean algal structures. The microcrystalline calcite debris were probably formed by grain-diminution (WOLF, 1965b) and the lime-mud may be finer grains of algae. 
The matrix commonly shows a weak flowage fabric so as to wrap around the framework constituents according to their configuration.

Internal cavities of gastropod shells are partially or completely filled by dark-grey micritic lime-mud. The remaining spaces are filled up by coarsegrained sparry calcite which has grown with the longer axes roughly normal to the shell wall. The calcite crystals increase in size away from the wall and form a mosaic structure. In some cases the central part of the cavity is occupied by quartz crystals, which filled up irregularly the interspace of the sparry calcite crystals. It is clear that the quartz crystals were diagenetically formed after the precipitation of the sparry calcite. The sparry calcite is also of diagenetic origin, and its primary fabric has been retained.

The occurrence of the limestone is restricted to the middle part of cyclic unit 8 of the Nagaiwa mine.

Feldspar crinoid biomicrudite

(ex. Pl. 47, Fig. 3)

This limestone consists mainly of crinoid debris and subordinately subangular to subrounded grains of feldspar (about 15\%) and quartz (about 10\%) with some volcanic rock fragments. Crinoid ossicles range mostly from 0.4 to $2.5 \mathrm{~mm}$., and feldspar and quartz grains are less than $0.4 \mathrm{~mm}$.

The matrix is very narrow. It consists of detrital lime-silt and -clay and calcite cement. The calcite cement occurs as an overgrowth of sparry calcite on crinoid grains with an optical continuity (syntaxial rim by BATHURST, 1958). There are some stylolites, along which brownish clay minerals occur.

This type of limestone occurs as thin beds at the basal part of cyclic unit 2 of the Nagaiwa mine and occupies the main part of cyclic unit 6 of the Sakamotozawa area. That of cyclic unit 6 represents a marginal facies of the crinoid biopseudosparrudite, as is observable in the Nagaiwa mine.

\footnotetext{
Algal biosparite

(ex. Pl. 46, Figs. 1, 2)
}

The main constituents of this limestone are debris of dasycladacean algae and oncolite. Crinoid ossicles and brachiopod shells are sparsely contained. Organic fragments have a moderately rounded surface, and range mostly from 0.5 to $1.5 \mathrm{~mm}$. in length and from 0.2 to $0.8 \mathrm{~mm}$. in width, and are disposed with the longer axis in the same direction. Some of them are coated by dark-grey, thin algal films.

The matrix of this limestone is recrystallized to some extent, but is originally fine-grained (mostly $0.1 \mathrm{~mm}$. in size) mosaic sparry calcite.

This limestone occurs in the middle to upper part of cyclic units 2,3 and 4 , and the lower part of cyclic unit 1 .

Algal biosparrudite

(ex. Pl. 48, Figs. 3, 4) 
This limestone is moderately well sorted, and its framework constituents are nearly the same as those of algal biosparite, consisting of fragments of oncolites, crinoids, dasycladacean algae and fusulines.

The matrix is relatively wider than that of other rock-types of the Sakamotozawa Limestone, and consists of a sparry calcite.

This limestone occurs in the middle to the upper part of cyclic units $2,3,4$, 5 and 9 , and is locally interbedded with algal biopseudosparrudite in the lower part of cyclic unit 1 .

$$
\begin{gathered}
\text { Fusuline biosparrudite } \\
\text { (ex. Pl. 48, Figs. 1, 2) }
\end{gathered}
$$

This limestone consists of fusulines, mainly Nagatoella minatoi and Pseudofusulina ambigua, with a small amount of dasycladacean algal debris.

The matrix is largely recrystallized to a sparry calcite which is 0.2 to $0.6 \mathrm{~mm}$. across. But it retains in part the original texture of elongate sparry calcite which has grown perpendicular to the walls of the framework constituents.

Secondary rhombohedral dolomite crystals are sometimes seen in the matrix and the fusuline shells.

The occurrence of this type of limestone is restricted to Member Sd.

\section{Crinoidal biomicrudite \\ (ex. Pl. 50, Fig. 3)}

The constituents are almost exclusively crinoid columnals and plates. They are contained as much as $50 \%$, not uncommonly $80 \%$ of the total constituents of the limestone. Other kinds of fossil and their debris are extremely rare, although a small amount of fusulines and small foraminifers are occasionally contained. The matrix consists primarily of micritic lime-mud, but is in patches recrystallized to fine-grained (mostly under $0.01 \mathrm{~mm}$.) pseudosparite. Especially, this limestone along fault zones in the Higashiyama quarry has a matrix of almost completely recrystallized coarse sparite, but retains relicts of a lime-mud matrix in some part such as in canals of crinoid columnals or unstrained narrow spaces enveloped grain-supported frame-works.

The lime-mud matrix is distorted, showing a flow fabric. Consequently recrystallization is taken place in strain-free areas adjacent to crinoid debris to form a grain-growth rim (BATHURST, 1958). It consists mostly of fine-grained mosaic calcite, but sometimes it forms a large syntaxial overgrowth in lattice continuity with a host. Some terrigenous muds and silts are also contained in the matrix, where fine graines (mostly between 0.03 and $0.05 \mathrm{~mm}$.) of opaque minerals are recognized.

The crinoid fragments sometimes have a grain-growth rim, which, in turn, grades into fine-grained pseudosparite, decreasing the grain size, and further into the lime-mud matrix with a hazy boundary.

A few open spaces, mostly from 2 to $4 \mathrm{~mm}$. across, are observed in one slide. 
They occur in a lime-mud matrix, and are subrounded patchy- or tortuous tubeshaped in section with a sharp boundary to the matrix. One of the cavities has internal sediments of lime-mud and fine-grained (commonly from 0.2 to $0.8 \mathrm{~mm}$., rarely over $1 \mathrm{~mm}$.) organic debris which partially filled the bottom side of the cavity before the diagenetic infilling of sparry calcite. Others are completely filled up with sparry calcite, that is drusy mosaics of BATHURST (1958), which show preferred orientation of the longest grain axis normal to the wall of the lime-mud matrix and increases in size away from the wall toward the center of the cavity, where it attains $1 \mathrm{~mm}$.

Many works have been made with regard to the genesis of open-spaces or voids and the process of internal filling and sedimentation (WoLF, 1965d; Perkins, 1963; Folk, 1959; ChILINGER, Bissel and WolF, 1967 and others). More sufficient material is necessary to determine the origin and paragenesis of the open-space structures under consideration, but they are probably boretubes made by burrowing animals.

Crinoid ossicles occur in various rock-types of limestone, but associated biogenic constituents demonstrate that Upper Palaeozoic crinoid colonies predominantly flourished in neritic environments. It is also suggested from their living organic structures that the conditions most suitable for the growth of crinoid colonies must have been below the wave base and in moderate currents of clear water which would have brought sufficient nutritious material for them. GEORGE (1958) considered that the crinoidal limestone of the Upper Caninia zone in south Wales was formed in shallow and clear waters of the open sea.

Thin-bedded argillaceous algal micrite with intercalated reddish-purple partings of limy clay is overlain with gradual transition by the crinoidal biomicrudite, which, in turn, is almost devoid of algal remains. This sequence seems to indicate the deepening of the sedimentary environment. The lime-mud matrix also indicates sedimentation in a calm environment not affected by strong wave action.

It is generally considered that crinoid skeletons are easily disjointed into individual segments by wave and current action after death. The contained crinoid columnals are, however, rarely as long as $10 \mathrm{~cm}$., very poorly sorted, and many of them do not show a distinct sign of abrasion. These features suggest that they deposited in and near their living sites. The crinoid biomicrudite of the cyclic unit 6 attains $55 \mathrm{~m}$. in thickness. Such a thick accumulation exclusively of crinoid ossicles implies a remarkably dense and continual growth of crinoids in the form of "crinoid forest".

The crinoid biomicrudite occurs typically in the cyclic unit 6 of the Nagaiwa mine. The coeval beds in the Sakamotozawa area are represented by crinoid biomicrudite and arenaceous crinoid biomicrudite with some debris of algae and fusulines. The contained crinoid ossicles are much more fragmentary and abraded than those of the Nagaiwa area, and seldom exceed $1 \mathrm{~cm}$. in size.

Algal pseudoöid biosparrudite (ex. Pl. 46, Figs. 6, 7) 
The term algal pseudoöid is used here for a small, spherical to subspherical, circumcrusted algal body on an organic or inorganic core. The limestone referred to algal pseudoöid biosparrudite consists predominantly of algal pseudoöids with some oncolites, fusulines, and debris of dasycladacean algae, gastropods, bryozoas and small foraminifers. The algal pseudoöids are of uniform size ranging mostly from 0.6 to $1.2 \mathrm{~mm}$. and occasionally up to $2.5 \mathrm{~mm}$. in diameter. They have uniformly concentric encrusting layers concordant to the core-shape and a relatively smooth outer surface (ex. Pl. 46, Fig. 6). The algal crust is composed of multiple, extremely thin laminae of grey to dark-grey, dense cryptocrystalline calcite, being usually thinner than a diameter of a detrital core. Compared with the algal crusts of the associated oncolites it is lighter in colour, composed of much thinner laminae, and more uniform in texture without spongy fabrics nor other incorporated allogenic impurities which are very common in the oncolitic algal crusts. The core consists of bioclasts mentioned above. In some cases algal pellet is also common as a core. The core of the algal pseudoöid is also of fairly regular size, mostly ranging from 0.4 to $1 \mathrm{~mm}$. in diameter. It is interesting that the associated fine-grained bioclasts smaller than $0.2 \mathrm{~mm}$. have no algal crusts. The matrix is composed of sparry calcite.

The algal pseudoöids of the Sakamotozawa Limestone are morphologically similar to circumcrusts, algal oölites and pisolites of the Lower Devonian algal reef complex of New South Wales described by WoLF (1965a, b and c). He referred them as subtypes to oncolites and considered them allochthonous in origin in the sense that they can be moved by currents and waves. The algal pseudoöids under consideration, however, are uniform in size and shape, and their crusts have a uniform thickness and continuation, without a truncated structure. These features suggest an autochthonous origin of algal pseudoöids, which were formed by the growth of algal filaments on bioclasts in the place of deposition. On the other hand, the associated oncolites are variable in size (mostly much larger than algal oöids) and shape, and have thicker algal crusts of different fabric, as mentioned above.

The above described textural and compositional features of algal pseudoöid biosparrudite indicate a uniform and continual agitation of water during the deposition. This limestone occurs in the basal part of cyclic unit 1 at the Higashiyama quarry.

\section{B. Cyclic sedimentation of the Sakamotozawa Limestone}

The Sakamotozawa Formation displays a sedimentary cycle which begins with the basal unit of conglomerate, lithic and feldspathic arenite and black shale, and is succeeded by calcareous sediments in the main part and completed with sandstone and shale. This sequence is regarded as probably reflecting a change from a transgressive phase (called the "Sakamotozawa transgression") through inundation phases to a regressive one. The cyclic sedimentation is also well recognized in minor order in the main part of the sequence, that is the Sakamotozawa Limestone (see Fig. 4). The pattern of a cycle is characterized by a gradual change of depositional environment from a shallow lagoonal sea to a slight 
deepened open sea and by a hasty change of environment from an open sea to a shallow lagoonal sea. The principal features that demonstrate the cyclic sedimentation of the limestone are as follows:

1. Change in thickness of a single stratum

In each cyclic unit, the thickness of a single stratum gradually increases upwards ranging from $5-10 \mathrm{~cm}$. in the basal part to about $1 \mathrm{~m}$. at the top.

2. Colour of limestone

In each cyclic unit, the limestone of the lower part is black to dark-grey in colour, but as the succession is followed upwards the limestone becomes gradually

Table 1. Relationship between the size-sorting and cementation of the matrix of detrital limestones

\begin{tabular}{|c|c|c|c|c|c|}
\hline Number & Member & $\begin{array}{l}\text { Mean } \\
\text { size } \phi\end{array}$ & $\begin{array}{c}\text { Standard } \\
\text { deviation } \phi\end{array}$ & $\begin{array}{c}\text { Degree of } \\
\text { sorting }\end{array}$ & $\begin{array}{l}\text { Kind of } \\
\text { matrix }\end{array}$ \\
\hline Ks. $\quad 2$ & Sb1 & 0.54 & 1.22 & ps & $\mathrm{m}$ \\
\hline Ks. 6 & " & 0.86 & 1.39 & 11 & $" \prime$ \\
\hline Ks. 8 & "I & 0.21 & 1.44 & " & $\prime \prime$ \\
\hline Ks. 46 & Sb3 & -0.05 & 1.01 & $\prime \prime$ & $" \prime$ \\
\hline Ks. 28 & $\mathrm{Sc}$ & 0.57 & 1.32 & $\prime \prime$ & $\prime \prime$ \\
\hline Ks. 30 & $\prime \prime$ & 0.86 & 1.19 & $\prime \prime$ & $\prime \prime$ \\
\hline Ks. 37 & $\prime \prime$ & 0.69 & 1.24 & " & " \\
\hline Ks. 58 & $\prime \prime$ & -0.11 & 1.18 & " & $\prime \prime$ \\
\hline Ks. 3 & $\mathrm{Sb} 1$ & 0.16 & 0.77 & $\mathrm{~ms}$ & $\mathrm{sp}+\mathrm{m}$ \\
\hline Ks. 7 & $\mathrm{Sb2}$ & 1.31 & 1.12 & ps & "I \\
\hline Ks. 158 & $\mathrm{Sd}$ & 0.32 & 1.17 & $\prime \prime$ & $\prime \prime$ \\
\hline Ks. $\quad 61-1$ & $\mathrm{Sb} 1$ & 1.57 & 1.30 & 11 & $\mathrm{sp}$ \\
\hline Ks. 61-2 & "' & 1.25 & 1.28 & 11 & $\prime \prime$ \\
\hline Ks. $\quad 61-3$ & $\prime \prime$ & 0.45 & 1.20 & " & $\prime \prime$ \\
\hline Ks. $\quad 62-1$ & $\prime \prime$ & 0.60 & 0.67 & mws & $\prime \prime$ \\
\hline Ks. $\quad 62-2$ & $\prime \prime$ & 0.24 & 0.66 & " & $\prime \prime$ \\
\hline Ks. 156 & $\prime \prime$ & 1.52 & 0.88 & $\mathrm{~ms}$ & $\prime \prime$ \\
\hline Ks. 157 & " & 1.21 & 1.12 & ps & $" \prime$ \\
\hline Ks. $11-1$ & $\mathrm{Sb} 2$ & 2.15 & 0.79 & $\mathrm{~ms}$ & $\prime \prime$ \\
\hline Ks. $11-2$ & " & 2.15 & 0.68 & mws & " \\
\hline Ks. 26 & $\prime \prime$ & 1.24 & 0.91 & $\mathrm{~ms}$ & $\prime \prime$ \\
\hline Ks. 148 & $\prime \prime$ & 0.60 & 0.87 & $\prime \prime$ & $\prime \prime$ \\
\hline Ks. 153 & $\prime \prime$ & 1.02 & 0.84 & $\prime \prime$ & $\prime \prime$ \\
\hline Ks. 205 & $\prime \prime$ & 0.18 & 0.88 & $\prime \prime$ & $\prime \prime$ \\
\hline Ks. 214 & $\prime \prime$ & 1.61 & 0.73 & $\prime \prime$ & $\prime \prime$ \\
\hline Ks. 215 & " & 0.44 & 0.99 & $\prime \prime$ & " \\
\hline Ks. 33 & $\mathrm{Sc}$ & 0.12 & 0.45 & ws & $\prime \prime$ \\
\hline Ks. 140 & $\prime \prime$ & 0.69 & 0.93 & $\mathrm{~ms}$ & $\prime \prime$ \\
\hline Ks. 199 & $\prime \prime$ & 2.23 & 0.48 & ws & $\prime \prime$ \\
\hline Ks. 238 & $\prime \prime$ & 0.88 & 0.68 & $" \prime$ & $\prime \prime$ \\
\hline
\end{tabular}

$\mathrm{ws}=$ well sorted, $\mathrm{mws}=$ moderately well sorted, $\mathrm{ms}=$ moderately sorted, $\mathrm{ps}=$ poorly sorted, $\mathrm{m}=$ lime-mud matrix, $\mathrm{sp}=$ sparry calcite matrix. 
lighter in colour. The massive limestone of the upper part is mostly grey to light-grey. That of Member Sb3 which is primarily composed of crinoid fragments is white to light-grey.

3. Reddish-purple limy clay

In many cases thin beds of reddish-purple limy clay are interbedded with oncolite biopseudosparrudite of the basal part of each cyclic unit. The thickness of each bed is in most cases less than $10 \mathrm{~cm}$. and occasionally attains $30 \mathrm{~cm}$. Each bed shows a gradual change from the lower dark-grey limestone to the upper reddish-purple clayey part, and its very top has a distinct boundary with the overlying dark-grey limestone. Besides, in some cases, the uppermost part has been more or less stained into reddish-purple colour. The limy clay is considered to have been produced by the contemporaneous weathering of limestone.

4. Matrix of limestone

It is one of the important features of the Sakamotozawa Limestone that the matrix of limestone is primarily made up of micritic lime-mud almost throughout the sequence as shown in Fig. 5. However, thin beds of limestone with a sparry calcite matrix are intercalated at several horizons. Organic detritus contained in the limestone with a sparry calcite matrix are better sorted than those of the limestones with a lime-mud matrix. Grain-size analysis of the organic debris for selected 29 specimens is shown in Table 1. The standard deviation value $\left(\sigma_{G}\right)$ of biomicrite and biomicrudite ranges from 1.01 to 1.44 , averaging 1.25 (poorly sorted). There are no samples that have the $\sigma_{G}$ values smaller than 1.0. But the $\sigma_{G}$ values of biosparite and biosparrudite range from 0.45 to 1.20 , averaging 0.87 (moderately sorted) for 18 specimens. This fact indicates that the limestone with a sparite matrix was formed in a sedimentary environment where the current action or agitation of water were conspicuous and accordingly the sediments were better sorted.

\section{Microbiofacies}

As is illustrated in Fig. 4, the biogenic constituents of the Sakamotozawa Limestone show a fairly regular change in their assemblage, quantity and mode of occurrence within each cyclic unit.

Oncolites are crowded in the lowest and/or lower part of a cyclic unit, being typically developed in the lower part of cyclic units 1, 2, 3 and 7. Examples from the cyclic unit 1 are shown in Fig. 3 on Plate 47 and Figs. 1-3 on Plate 50. The matrix of the limestone with oncolites is pseudosparite and micritic lime-mud, and contains small organic debris and terrigenous sand grains. The depositional environment of oncolite biopseudosparrudite is discussed in Chapter III-A. Oncolites decrease in size and quantity gradually upwards in a cyclic unit, and those of the middle part are often fragmentary or apparently abraded. Algal oölites also occur in the middle part. In the upper part encrusted algal bodies or algal oölites are rarely found, and very fragmentary fine-grained algal debris predominate.

Dasycladacean and codiacean algae and their debris occur almost throughout the sequence of the Sakamotozawa Limestone, and generally are abundant at the level succeeding to the oncolite limestone mentioned above. The most typical 


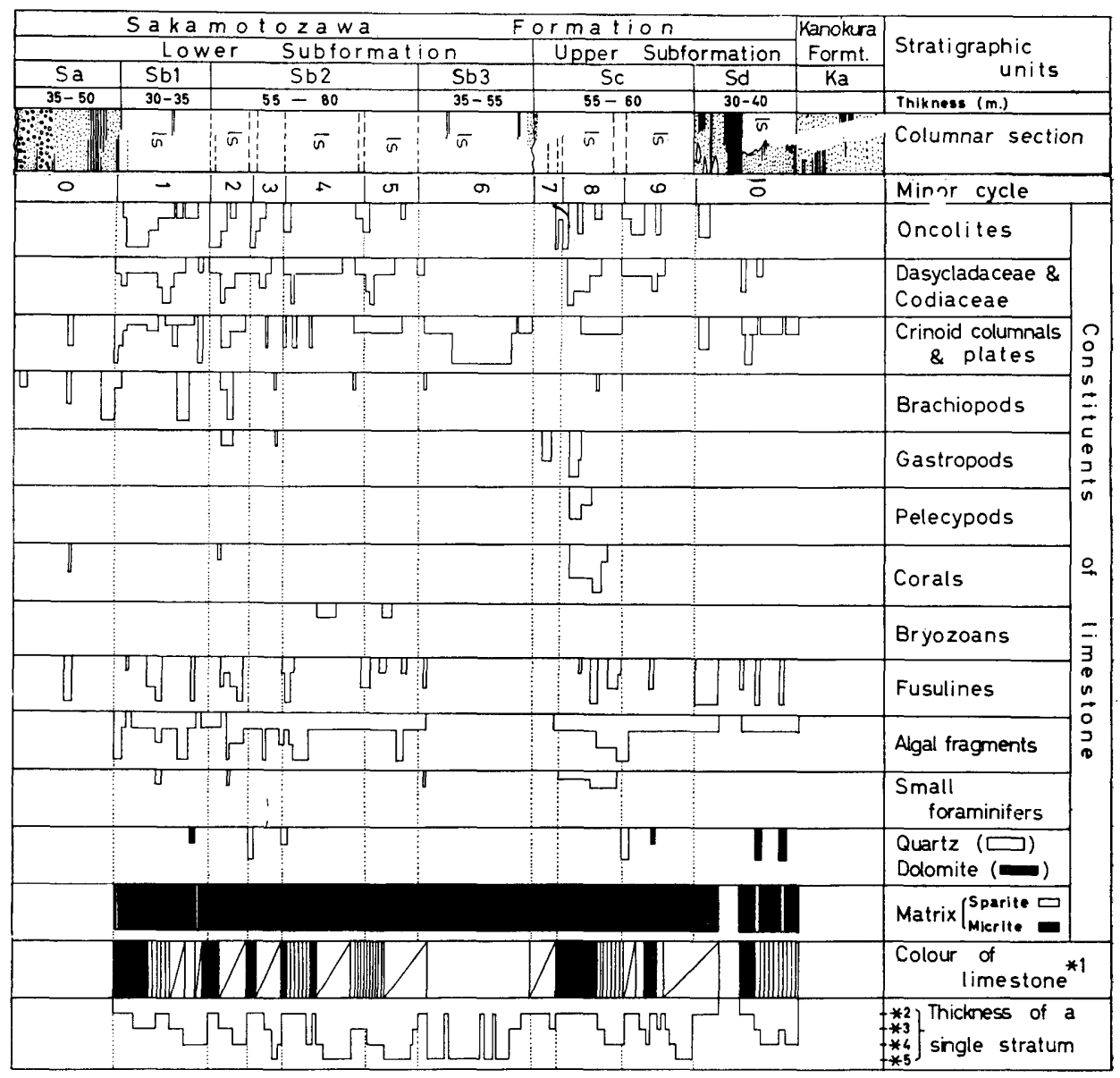

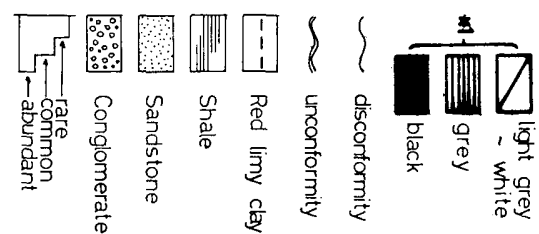

Fig 4. Vertical variation of main constituents of the Sakamotozawa Limestone.

*2: thin bedded $(5-20 \mathrm{~cm}) ; * 3:$ thin-bedded $(20-50 \mathrm{~cm}) ; * 4$ : thickbedded $(50-100 \mathrm{~cm})$; $* 5$ : massive (over $1 \mathrm{~m})$.

example is seen in the middle part of the cyclic unit 8 , where nearly complete specimens of Mizzia velebitana SCHUBERT occur abundantly in a dark-grey pseudosparite matrix. The associated organic remains such as small simple corals and fusulines are also almost complete. However, in other cyclic unit they are generally fragmentary and accompanied by algal oölites and incomplete oncolites mentioned above. WOLF (1965c) attempted to subdivide calcareous algal sediments and considered that the algae are gradationally disintegrated into frag- 
ments of various grades of fineness and structure. In case of the Sakamotozawa Limestone it is noticed that, as the sequence of a cyclic unit is followed upwards, oncolites and well-preserved dasycladacean algal thalli decrease and fine-grained algal debris and micritic lime-mud gradually increase.

Brachiopods occur abundantly in the biomicrite and biomicrite beds with a reddish-purple limy clay parting of the lower part of the cyclic unit 1 and in the biomicrudite of the middle part of the cyclic unit 2. They are also found in the biosparrudite bed at the lower part of the cyclic unit 1 and of the middle to upper part of the cyclic unit 2.

Throughout the Sakamotozawa Limestone, crinoid fragments are an important constituent of limestone next to calcareous algae. The crinoidal limestone beds are best in the cyclic unit 6 and also intercalated in the middle to upper part of the cyclic units 1,2 and 3 .

Fusulines occur at many horizons in the Sakamotozawa Limestone, and are in general very common or abundant in the middle part of each cyclic unit. In many of these beds the contained fusulines are few in number of species but are commonly very abundant in individuals. The shape of their shells corresponds fairly distinctly to the lithology of limestone in which they occur.

An elongate subcylindrical species of Monodiexodina (Ferganites) langsonensis occurs commonly in biomicrite or sometimes biomicrudite beds of the middle to upper part of the cyclic units 2 and 3. They are often concentrated in particular laminae keeping a constant direction of shells. The limestone in which they occur contains fairly well-sorted fragments of crinoids and calcareous algae and has a narrow lime-mud matrix. It sometimes contains terrigenous quartz sands and silts. The above lithological characters may suggest an environment under some agitation of water currents or wave agitation, but the contained fusulines are rather complete. Rugosofusulina alpina which has a relatively thin-walled, elongate shell is commonly found in homogeneous fine- to medium-grained biomicrites.

Many casts of long, subcylindrical, unidentified fusuline shells are contained in fine-grained sandstones of Member Sa. They are disposed mostly in the same direction. A similar mode of occurrence of elongate fusulines in sandstone is also well known as "Matsubaishi" (pine-needle stone in Japanese; Monodiexodina matsubaishi FUлгмото, 1956) in the Kanokura Formation.

Large globose species such as Zellia nunosei HANZAwa and Pseudoschwagerina (Robustoschwagerina) HANZAWA are common in biomicrite or biomicrudite beds which contain oncolites and a small amount of angular, poorly-sorted organic fragments. Although these species occur in a lime-mud matrix, the outer one or two volutions of their shells are commonly abraded. As a spherical shape is most liable to transportation by currents, probably they must have been transported with some other organic fragments from their living site for some distance.

Thick fusiform species such as Pseudofusulina vulgaris (s. 1.) is most abundant in the limestone with a micritic lime-mud matrix and poorly-sorted organic debris at the middle part of the cyclic unit 8 . Their shells are almost 
completely preserved. Large fusiform to inflated fusiform species of Paraschwagerina (Acervoschwagerina) and Rugosofusulina etc. occur sporadically not only in thin-bedded biomicrites but also in relatively massive ones. Associated organic constituents are mainly algal fragments, showing very poor sorting.

Nipponitella explicata, an uncoiled aberrant species, is in most cases contained in homogeneous biomicrites consisting mainly of fine-grained debris of calcareous algae and crinoids. It also occurs occasionally in fine-grained biosparites. Despite its delicate and thin-walled shell it is almost complete.

Corals are rather rare except in the middle part of the cyclic unit 8 of the Nagaiwa area where small simple corals are fairly common. Small colonies of Michelinia are also found from the same part.

Gastropods occur in the middle to upper part of each cyclic unit. The limestone in which they occur has a lime-mud matrix. Several species are found most commonly in the middle part of the cyclic unit 8 of the Nishiyama quarry and the eastern slope of Tashiroyama.

To sum up, in each cyclic unit the lower part is characterized by the development of oncolitic calcareous algae. Dasycladacean and codiacean algae and elongate subcylindrical or thick fusiform fusuline species occur most abundantly in the middle part. Organic constituents, particularly debris of calcareous algae, of rudite size gradually decrease upwards in each cyclic unit, and the limestone of the upper part consists of bioclasts of arenite size with a rather large amount of lime-mud matrix. The lime-mud seems to have been derived largely from calcareous algae and subordinately from other kinds of organisms, such as gastropods, brachiopods and crinoid fragments. The vertical variation of the main constituents in the described sequence is shown in Fig. 4.

From the above described vertical change of bio- and litho-facies the following conclusion may be led. The Sakamotozawa Limestone consists of ten units, each of which represents a minor cycle of sedimentation as indicated in Fig. 3. The cyclic unit is most typically displayed by Member Sb2 exposed on the Nishiyama quarry. It begins with thin-bedded $(5-10 \mathrm{~cm}$.) oncolite biopseudosparrudite beds with thin partings of the reddish-purple limy clay, is succeeded by bedded $(15-30 \mathrm{~cm}$.$) , dark-grey biomicrite beds frequently with dasycladacean biomicru-$ dite, and ends with thick-bedded $(50 \mathrm{~cm} .-1 \mathrm{~m}$.) to massive (over $1 \mathrm{~m}$.) algal biomicrudite and biomicrite beds with occasional bands of algal biosparite, -biosparrudite, and crinoidal biomicrite and calcarenite. Thin beds of black calcareous shale and fine-grained lithic arenite are sometimes intercalated in the lower part of each cyclic unit.

The cyclic unit in the Sakamotozawa Limestone is regarded as representing a serial change of the sedimentary environment. Namely, it begins with the sediments which were formed under a very shallow intertidal condition of a probably restricted water (possibly a lagoon), with an intermittent desiccation of water at times, followed by those of a slightly deepened near-shore to a somewhat offshore environment of open neritic sea where washing of sediments was taken place by agitating water or currents of moderate intensity, and ends with thin transitional part which is succeeded by the next cyclic unit. 


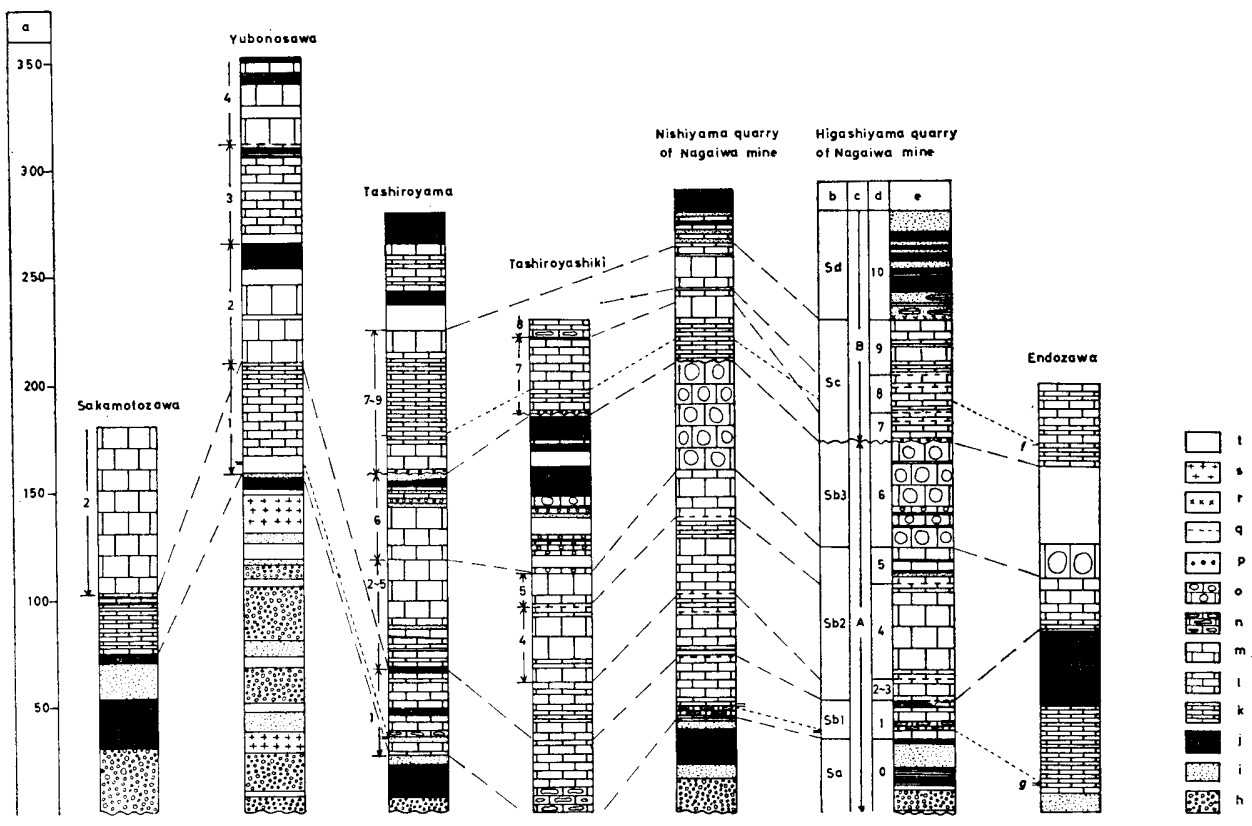

Fig. 5. Columnar sections of the Sakamotozawa Formation along the seven selected routes in the Sakamotozawa-Nagaiwa area, showing ten sedimentary cycles.

a. thickness in m.; b. member; c. major cycles; d. minor cycles; e. columnar section; f. Pseudofusulina vulgaris; g. Pseudoschwagerina (Zellia) nunosei; h. conglomerate; i. sandstone; j. shale; k. thin-bedded limestone $(5-20 \mathrm{~cm}) ; 1$. thin-bedded limestone $(20-50 \mathrm{~cm}) ; \mathrm{m}$. thick-bedded limestone; $\mathrm{n}$. oncolitic limestone; o. crinoidal limestone; $\mathrm{p}$. conglomeratic limestone; q. red limy clay; r. iron bed; s. dike rock; t. unexposed; -- correlation of cyclic units; $\cdots . .$. . correlation of fossils.

\section{Discussion}

The Lower Permian Sakamotozawa Formation has considerable peculiarities not only in lithofacies but also in sedimentological characters, as compared with the Late Palaeozoic sediments of other areas of Japan.

The Sakamotozawa Limestone is well stratified as mentioned before. No such well-bedded limestones are present in other regions of Japan, where the limestone is massive, as is well exemplified by the Akiyoshi, the Atetsu, the Akasaka and the Ibukiyama Limestone. It has thin intercalations of shale, sandstone and granule- to pebble-conglomerate, but is not associated with chert and submarine volcanic sediments. In this respect it differs from the limestones of the Upper Carboniferous-Lower Permian Tobiishi Group and its equivalents and of Permo-Triassic Sambosan Group in the Outer Zone of southwest Japan. Twelve lithologic types of the Sakamotozawa Limestone, which mostly have a micritic matrix, can be summarized into four groups, i.e. algal limestone, crinoidal limestone, fusuline limestone and gastropod limestone, on the basis of the main constituents. Of these the algal limestone is most predominant. It is composed not only of blue green algae but also of dasycladacean and codiacean algae, 
although their quantity, mode of occurrence and kinds of species change vertically and horizontally. Especially oncolite is characteristic of this limestone. So far as has been known, it is very rare in the Palaeozic carbonate sediments in Japan. The presence of oncolite can be used as good evidence for that a restricted, very shallow, calm environment of sea-waters had prevailed during the deposition.

The cyclic sedimentation is another outstanding character of the Sakamotozawa Limestone, as has been described in detail in Chapter III-B. This phenomenon has not been noticed in the Late Palaeozoic limestone sequence in Japan.

The cyclic feature of the marine limestone sequence has been described from several regions outside Japan. DIXoN and VAughaN (1911, quoted in DUFF et al., 1967) discriminated two phases of a cycle, standard phase and a lagoonal phase, in the Lower Carboniferous limestone of the Gower Peninsula, South Wales. The former is characterized by crinoidal and oölitic limestone, indicating shallow but open sea sediments. The latter is represented by finegrained and less fossiliferous limestones with a few species of bivalves and algal growths, suggesting extremely shallow waters effectively isolated from the open sea.

PIRLET (1963, quoted in DUFF et al., 1967) described a cyclic calcareous sequence of the Upper Visean of Belgium. It consists of skeletal calcarenite with an erosion or scour surface at its basal part and of poorly fossiliferous calcilutite and stromatolitic limestone in the upper. He considered that the lower part was accumulated in an open sea, and the upper on an extremely shallow lagoonal platform.

These two examples of cyclic sediments are of stable shelf area. In these examples the sedimentary environment of the limestone containing stromatolitic algae may be comparable with that of the oncolite biopseudosparrudite of the Sakamotozawa Limestone. However, the pattern of the cyclic sedimentation of the Sakamotozawa Limestone which is represented by a change of environmental condition from a lagoonal sea to an open one shows a reversed order to that of two examples as mentioned above.

As other types of cyclic shelf sediments which contain carbonate rocks such successions as limestone-dolomite, limestone-argillaceous, clay-sandstonelimestone and sandstone-shale-limestone-shale etc. have been recognized in the Pennsylvanian and Lower Permian of Kansas and adjacent areas. These cycles also have an order from a transgressive phase to a regressive one, that is, a change of environmental condition from an off-shore sea to a near-shore and lagoonal one (MOORE, 1959).

Another example of a cyclic sequence of limestone which has some terrigenous intercalations is that of the Lower Pennsylvanian Moleen Formation in the Cordilleran geosyncline (DoTT, 1958; BIssEL, 1964). According to DoTT (1958), each cycle, which is $10-20 \mathrm{~m}$. in thickness, begins with a diastem produced by submarine scouring, and consists of the following four units in ascending order: (1) non-carbonate sediments (silt, sand and conglomerate), (2) fossil hash calcarenite, (3) coqquinite or coquinoid limestone, and (4) fine 
and cherty limestone. He explains that the cause of such a cyclic sedimentation can be attributed to alternations of agitated and quiet bottom conditions which have taken place in relation to the tectonic movement of geosynclinal period. He also stated that the clastic sediments were mainly supplied from a island belt produced by orogeny in eugeosyncline, and some of them came from upwarps and platforms within the miogeosyncline itself and partly from a craton in the east.

The cyclic change of environmental conditions of the Sakamotozawa Limestone resembles that in the stable shelf or miogeosyncline, as described by Dixon and Vaughan, PIRLET and DotT. It is noteworthy, however, that the cyclic pattern of the Sakamotozawa Limestone shows a reversed order to that of the other areas outside Japan.

The cause of the cyclic sedimentation is not definitely known, but two main controlling factors have been discussed by authors. One is the periodic change of the sea level caused by glaciation and the other is the tilting and minor crustal warping caused by tectonic movement. The change of the sea level by glaciation would present the worldwide effect, so it should give rise to a cyclic sedimentation not only in the epicontinental regions but also in the mobile belts. Actually cyclic patterns differ from place to place, and in some regions no distinct cyclic sediments can be seen at all. This fact may be partly due to the local difference of the geographical and environmental conditions. Furthermore, it should not be neglected that the cyclic movement caused by eustatic pulsation throughout the broad area would be modified or obliterated by the oscillation caused by local tectonism in the mobile belts. It is accordingly considered that the mode of the cyclic sedimentation in the mobile belts should have a local peculiarity caused by duplication of the two controlled factors.

In Japan located in the circum-Pacific mobile belt, tectonic movements had already occurred in the Carboniferous period in the southern Kitakami and certain other regions. Geosynclinal sedimentation was in progress in northern Kitakami and other regions in the same period. In such tectonically unstable regions, it is difficult to make clear how the eustatic movement by glaciation affected the cyclic sedimentation. However, as the cyclic sedimentation is not recognized widely in the limestone complexes and the associated non-calcareous sediments in other tectonic provinces of southwest Japan, it seems probable that a provincial tectonic movement played the most important role in the cyclic sedimentation of the Sakamotozawa Formation. Furthermore, it is considered that the peculiar cyclic pattern of the formation is attributed to a mode of a tectonic movement particular to the southern Kitakami. But, for a precise interpretation of the cause and significance of the cyclic feature, it is required to investigate a lateral change of the cyclic pattern. 


\section{Sedimentology of the sandstones of the Sakamotozawa and Kanokura Formation}

\section{A. Petrology}

1. Petrographic samples and method of study

The localities where the examined specimens of sandstone were collected and their stratigraphic positions in the Sakamotozawa Formation are shown in Figs. 2 and 3, respectively. In addition, sandstone specimens from Member Ka of the Kanokura Formation in the Nagaiwa-Sakamotozawa area, and from the Kacchizawa Member in the type area of the Kanokura Formation have also been examined (Fig. 3).

The relative amount of major constituents of sandstone is measured by the use of a microintegrator through thin sections under a microscope. Types of sandstone are classified according to OKADA's scheme (1968). The roundness of grains is determined by PowERs' silhouette scale (1953) under the microscope.

The size analysis is carried out by the measurement of the largest diameter of every kind of grains, because the quartz content is extremely variable and sometimes very scanty. Especially, specimens, in which plastic deformation of sand grains is negligible, are selected for the size analysis. Some statistic parameters are calculated from a cumulative curve drawn on the probability paper in accordance with the formula of FOLK and WARD (1957).

The sandstones of the Sakamotozawa and Kanokura Formations wholly belong to the arenite of OKADA's classification. Two main types are recognized in the arenite and each of the main types is further subdivided into two subtypes, when kinds of minerals and rock fragments are taken into consideration. The stratigraphic position of the four types of sandstone is shown in Fig. 3.

2. Types of sandstone and mode of their occurrence

a. Lithic arenite (Type Ia; Pl. 51, Figs. 1-3): The sandstone of this type is characterized by a high content of rock fragments, which occupy 50 to 85 per cent of the total composition. The rock fragments consist on the average of 40 per cent black shale, 20 per cent chert and 40 per cent volcanic rocks. Feldspar and quartz are scanty in content.

The specimen Ks. 109 is unusual in composition as compared with the normal Sakamotozawa sandstone in that subangular to subrounded chert grains occupy as much as 72 per cent of the total composition. Fragments of pitchstone are contained in the specimen Ks. 108-2. Radiolarians are found in the chert grains of the specimen Ks. 81-1.

Kinds of rock fragments of the Ia sandstone somewhat differ from those of the Sakamotozawa conglomerate. The conglomerate consists mainly of pebbles of sedimentary rocks, such as chert and shale, and dike rocks (porphyrite), but no pebbles of andesite or dacite have been found.

The grains of this type of sandstone collected from the Nagaiwa area are frequently transformed into elongated shapes, and show to a certain extent preferred grain orientation owing to shearing stress. The shale grains are more strongly deformed than chert and porphyrite grains. The quartz grains are 


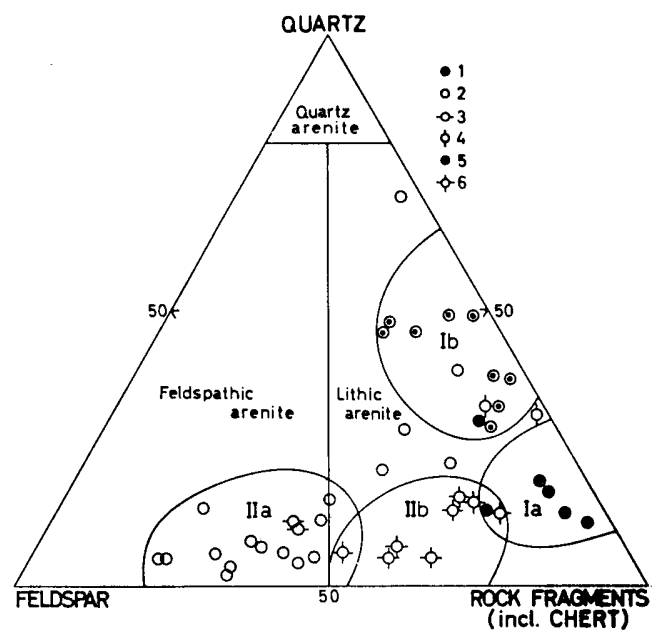

Fig. 6. Composition of the Sakamotozawa and Kanokura sandstones, showing four sandstone types [on OKADA's diagram (1968)].

1. Lower part of Member Sa; 2. Middle and upper part of Member Sa; 3. Member Sbl.; 4. Member Sc; 5. Member Sd; 6. Kanokura Formation.

not deformed.

The roundness of chert and quartz grains of the Ia sandstone is 0.26 (subangular) and at best 0.3 This roundness is better than that in other types of sandstone in the Sakamotozawa and Kanokura Formations.

Sandstone of this type stratigraphically occurs below the Sakamotozawa conglomerate and is also intercalated in the same conglomerate in a lenticular form. It is exposed at Endozawa, the Nishiyama quarry of the Nagaiwa mine and on the eastern slope of Tashiroyama. The thickness of a single sandstone bed ranges from $50 \mathrm{~cm}$. to $1 \mathrm{~m}$. and the total thickness of sandstone beds is not over 5 meters. Sandstone exhibits commonly yellowish brown to light greyish brown colour. At Endozawa, the sandstone bed unconformably overlies limestones of the Carboniferous Nagaiwa Formation and gradually changes upwards into granule conglomerate.

b. Feldspathic arenite (Type IIa; Pl. 51, Figs. 4, 5, 7; Pl. 52, Fig. 6) : The type IIa sandstone is mainly composed of plagioclase $(40-70 \%)$ and rock fragments $(30-50 \%)$. The quartz content is usually less than 15 per cent. The rock fragments are largely of volcanic rocks and are characterized by pyroxene andesite and rhyolitic or dacitic rocks. Clasts of shale, chert and porphyrite are also contained in a small amount in every specimen. Plagioclase usually shows twining-structure, and is frequently replaced by calcite and chlorite along the lamellae. Quartz is simple and unstrained and bears no inclusion. The grains of this sandstone are angular to subangular (the value of roundness 0.23 on the average).

This sandstone is medium- to coarse-grained, rarely fine-grained and light green to greenish grey in colour. It occurs in the middle and upper parts of 
Member Sa and the lower part of Member Sbl.

In the middle part of Member $\mathrm{Sa}$, a single sandstone bed is usually massive. ranging from 1 to $2 \mathrm{~m}$. in thickness. It is occasionally divided into two or more beds, each of which is $30-50 \mathrm{~cm}$. in thickness and interbedded with thin granule conglomerate beds.

These sandstone beds can be traced for a great distance in the Kesen area, though it shows a lateral change in lithology and thickness. The thickness of the sandstone beds is not over $15 \mathrm{~m}$. at the maximum in the type Hikoroichi area. Grading-structure is observed in this sandstone at Endozawa. Good exposures are seen at Endozawa, Iwashita and Sakamotozawa in the surveyed area.

The sandstone of the upper part of Member Sa belongs to this type. It is fine- to medium-grained and greenish brown. The thickness of sandstone beds is variable.

Thin-bedded (generally $20 \mathrm{~cm}$., rarely $50 \mathrm{~cm}$. thick), fine- to mediumgrained, light grey to light brownish grey sandstone which is intercalated in thin-bedded limestone of Member Sb1 also belongs to this type. Several exposures of this sandstone are recognized in the Higashiyama and Nishiyama quarries and in a trench cut along the western slope of the hill of Tashiroyama.

c. Lithic arenite (Type Ib; Pl.51, Fig. 6; Pl.52, Fig. 3): The sandstone of this type is composed of $30-50$ per cent of quartz, 30-60 per cent of rock fragments and a small amount of feldspar grains. The rock fragments have the composition of shale (about $40 \%$ ), chert (about $20 \%$ ) and the volcanic rocks (about $20 \%$ ). Thus, the composition of the rock fragments of the Ib sandstone is similar to those of the Ia sandstone. In the sandstone of type Ib, however, the content of quartz increases while that of the sedimentary rock fragments decreases.

The average value of roundness is 0.25 (subangular). Subrounded or rounded quartz grains are sporadically contained.

Medium- to coarse-grained sandstones of the basal part of Member Sc and the lower part of Member Sd belong to the type Ib.

d. Lithic arenite (Type IIb; Pl. 51, Fig. 8; Pl. 52, Figs. 4, 5): The type IIb sandstone consists of 50-70 per cent of rock fragments, 20-40 per cent of plagioclase and $10 \pm 5$ per cent of quartz.

The rock fragments are those of rhyolitic or dacitic rocks and some pyroxene andesite. The shale grains are few, but they are contained in all the examined specimens. In some specimens the fragments of limestone and amphiboles are contained. The main composition of this type is similar to that of the feldspathic arenite (type IIa). The two types are distinguished by a ratio of the content of the rock fragments and feldspar.

The roundness of the sand grains is the worst of all the types of the sandstones in the Sakamotozawa area, showing the average value of 0.21 (angular).

Sandstones of Member $\mathrm{Ka}^{*}$ in the Nagaiwa-Sakamotozawa area and the Kacchizawa Sandstone Member, the lower member of the Middle Permian Kano-

* Member $\mathrm{Ka}$ is poorly exposed, and does not contain effective fossils to determine precisely its geological age. It may be, however, correlated to the Kacchizawa Sandstone Member (ONUKI, 1956) because it overlies Member Sd. 
Table 2. Mineralogical maturity, sorting and roundness of sandstones of the Sakamotozawa and Kanokura Formations

\begin{tabular}{c|c|c|c|c|c}
\hline Member & Sal & Sa. m-u & Sb1 & Sd & Ka \\
\hline Types of sandstone & $(\mathrm{Ia})$ & $(\mathrm{IIa})$ & $(\mathrm{IIa})$ & $(\mathrm{Ib})$ & $(\mathrm{IIb})$ \\
\hline Quartz+Chert & 0.96 & 0.23 & 0.13 & 3.62 & 0.14 \\
\hline Feldspar+Rock fragments & $\begin{array}{c}0.77 \\
(\mathrm{~ms})\end{array}$ & $\begin{array}{c}0.89 \\
(\mathrm{~ms})\end{array}$ & $\begin{array}{c}0.96 \\
(\mathrm{~ms})\end{array}$ & $\begin{array}{c}0.93 \\
(\mathrm{~ms})\end{array}$ & $\begin{array}{c}1.14 \\
(\mathrm{ps})\end{array}$ \\
\hline Sorting $\left(\sigma_{\mathrm{G}}\right)^{*}$ & $\begin{array}{c}0.26 \\
(\mathrm{SA})\end{array}$ & $\begin{array}{c}0.23 \\
(\mathrm{~A})\end{array}$ & $\begin{array}{c}0.26 \\
(\mathrm{SA})\end{array}$ & $\begin{array}{c}0.25 \\
(\mathrm{SA})\end{array}$ & $\begin{array}{c}0.21 \\
(\mathrm{~A})\end{array}$ \\
\hline
\end{tabular}

* Calculated by the formula of FoLK and WARD (1957)

$\left[\sigma_{G}=\frac{\phi_{84}-\phi_{16}}{4}+\frac{\phi_{95}-\phi_{5}}{6.6}\right]$

** According to the PowERs' roundness scale (1953).

$\mathrm{ms}=$ moderately sorted, $\mathrm{ps}=$ poorly sorted, $\mathbf{A}=$ angular, $\mathrm{SA}=$ subangular .

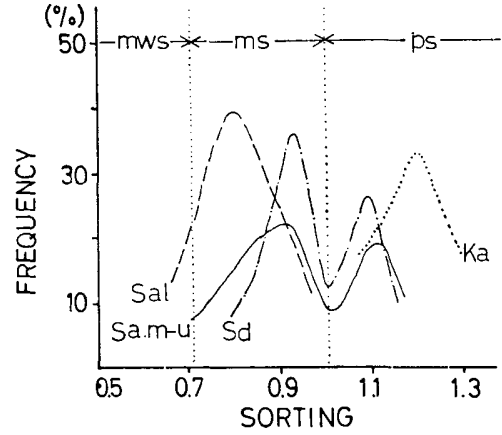

Fig. 7. Frequency distribusion of size-sorting of the examined sandstones.

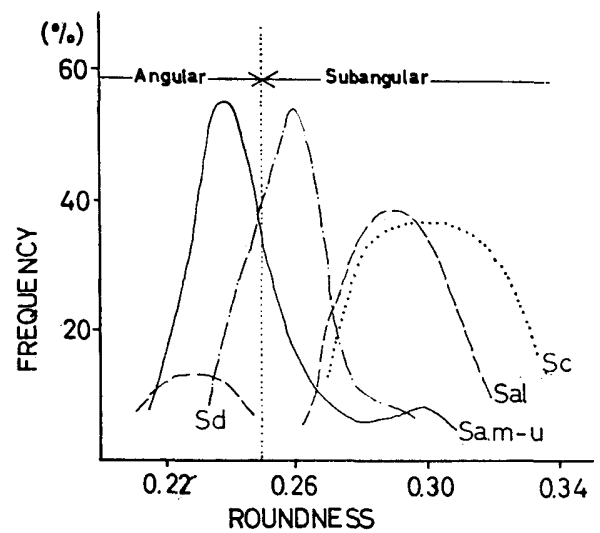

Fig. 8. Frequency distribution of roundness of the examined sandstones.

kura Formation in its type area, belong to this type.

Member Ka consists of thin to thick bedded alternation of shale and sandstone with intercalated thin lenticular beds of granule to pebble conglomerate at some horizons. The Kacchizawa Member begins with a thin bed of granule to pebble conglomerates and consists mainly of medium- to coarse-grained, light greenish grey, thick-bedded to massive sandstones. Cross lamination is frequently observed in sandstone beds of the lower part of the member.

Five specimens of the lower part of the Kacchizawa Member and three specimens of Member Ka of the Nagaiwa area are examined in this study.

\section{Grain size distribution}

a. Mean size (Graphic Mean, $\mathrm{Mz}$ ): Values of the mean size $(\mathrm{Mz})$ of the examined sandstone specimens of the Sakamotozawa and Kanokura Formations range from $0.84 \phi(0.56 \mathrm{~mm}$.) to $2.98 \phi(0.126 \mathrm{~mm}$.), and the average of them is $1.66 \phi(0.33 \mathrm{~mm}$. $)$. The average $\mathrm{Mz}$ values for individual members are as follows: 
Sa (lower part) $=1.31 \phi(0.40 \mathrm{~mm}$. $), \mathrm{Sa}$ (middle to upper part) $=1.48 \phi(0.36$ $\mathrm{mm}.), \mathrm{Sb1}=1.45 \phi(0.37 \mathrm{~mm}),. \mathrm{Sc}=1.61 \phi(0.33 \mathrm{~mm}),. \mathrm{Sd}=2.17 \phi(0.22 \mathrm{~mm}$.$) and$ $\mathrm{Ka}=1.69 \phi(0.31 \mathrm{~mm}$.).

b. Standard deviation (Sorting, $\left.\sigma_{G}\right)$ : The standard deviation $\left(\sigma_{G}\right)$ of individual sandstone specimens ranges from 0.60 (moderately well sorted) to 1.60 (poorly sorted) for the Sakamotozawa and Kanokura Formations. The average value of 40 specimens is 0.93 (moderately sorted).

The average $\sigma_{G}$ value of the sandstone (type Ia) from the lower part of Member Sa is 0.77 (moderately sorted), showing the best sorting in the sandstone of the Sakamotozawa and Kanokura Formations. No specimen exceeds 1.0 in $\sigma_{G}$ and the range of $\sigma_{G}$ is narrow (see, Table 2; Fig. 7).

Sandstones (type IIa) of the middle and upper parts of Member Sa have a mean $\sigma_{G}$ value of 0.89 (moderately sorted) to 1.38 (poorly sorted).

It is noticed that sandstones of Member Sb1 is poorly sorted. Nevertheless, grains mainly of plagioclase and volcanic rocks are moderately well rounded. As the examined specimens from Members Sb1 and Sc are limited in number, it is impossible to discuss any significance of the $\sigma_{G}$ value in comparison with that in other members.

The sandstone of Member Sc, which has broader matrix (about 10\%) than that of other members of the Sakamotozawa and Kanokura Formations, has a mean $\sigma_{G}$ value of 1.17 , and worst in sorting among all the sandstones of two formations.

c. Skewness (SkI): Of the 47 analyzed specimens, 20 are nearly symmetrically skewed, and 3 strongly finely skewed. The others are finely skewed.

d. Interrelation of the size parameters

(1) Relation between mean size and major constituents: There is a clear relation between the matrix content and mean size in that the matrix increases in amount with decreasing grain size (Fig. 9), as shown by OKADA (1966).

The relation that the quartz content increases with decreasing grain size is recognized in sandstones of the Sakamotozawa and Kanokura Formations (Fig. 10). The same trend has been shown by OKADA (1966) in the Cambrian and Silurian sandstones in north Wales. Any significant relation is not deduced between feldspar content and grain size of sandstones of the Sakamotozawa and Kanokura Formations. On the contrary, SHIKI (1961) and OKADA (1966)

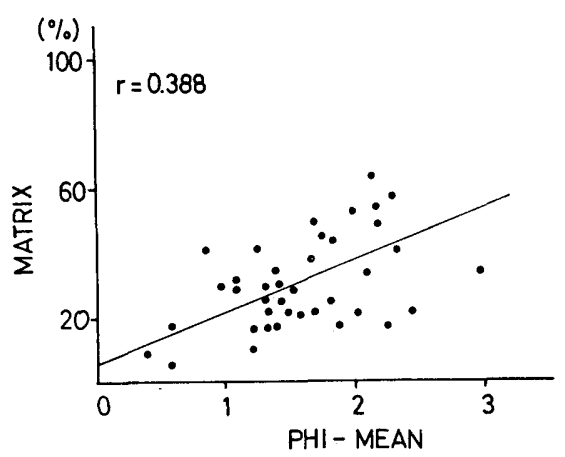

Fig. 9. Matrix content versus mean-size. 


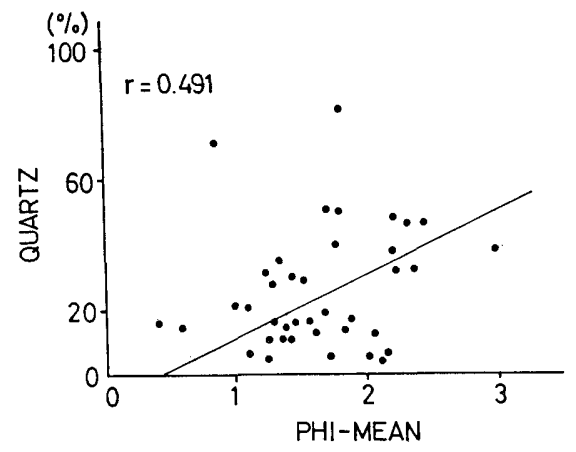

Fig. 10. Quartz content versus mean-size.

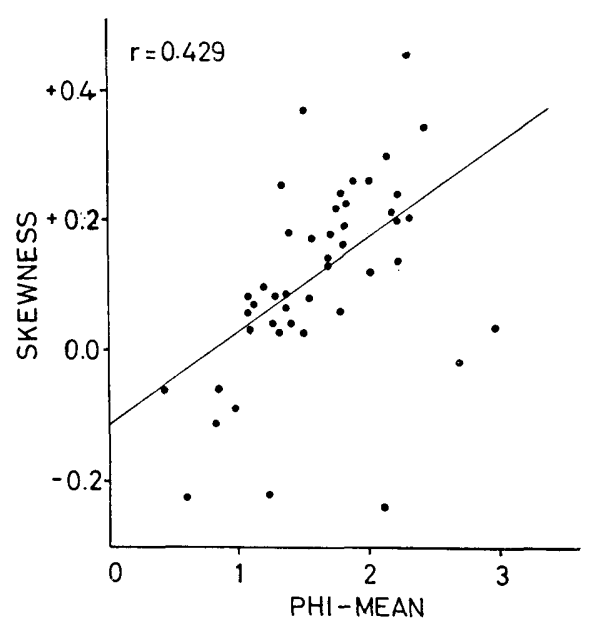

Fig. 11. Skewnss versus mean-size.

showed some linear relationships between them.

(2) Grain size versus standard deviation: No significant correlation exists between grain size and sorting in sandstones of the Sakamotozawa and Kanokura Formations.

(3) Grain size versus skewness: Fig. 11 demonstrates that skewness increases with decreasing grain size. This relationship agrees with the sinusoidal trend described by FOLK and WARD (1957) for the grain size between 1 and $3 \phi$.

4. Heavy minerals

The heavy mineral assemblage of sandstones of the Sakamotozawa and Kanokura Formations is summarized in Fig. 12.

The heavy minerals of the types Ia, IIa and Ib sandstones are characterized by a high content of opaque minerals, attaining to 94 per cent of the total heavy residues.

The transparent minerals, that occupy the remaining several per cent, are zircon, hornblende, augite, tourmaline, garnet, biotite and hypersthene, of which zircon is as abundant as 55 to 98 per cent.

To the contrary, opaque minerals drop down to 50 per cent in content on the average in the IIb type sandstone. Hornblende and augite contents increase with descreasing content of zircon in this sandstone type.

The above mentioned assemblage of heavy minerals seems to indicate that the source area was primarily composed of volcanic rocks. This condition seems to have continued during the deposition of the sequence. Many of the minerals are almost constant in amount throughout all the types of sandstones, Ia, Ib and IIa, whereas hornblende and augite increase remarkably in the IIb type sandstone.

Generally speaking, the heavy mineral assemblage of sandstones with high mineralogical maturity and roundness (type I) is characterized by stable minerals such as zircon and garnet. On the other hand, sandstones with low mineralogical maturity and poor roundness is characterized by relatively unstable heavy minerals such as hornblende and augite. 


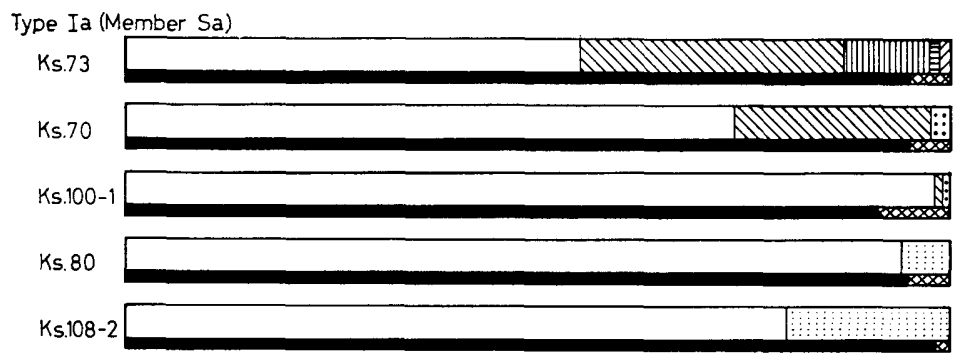

Type Ila (Member Sa)

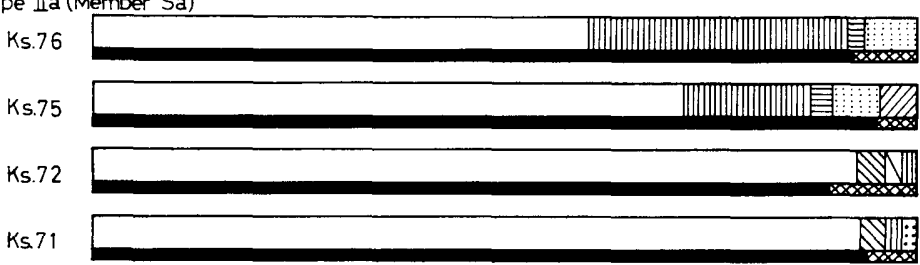

Type Ila (Member Sb1)

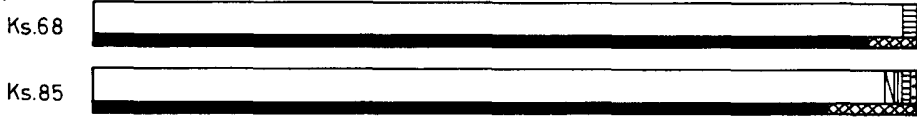

Type Ib (Member Sd)

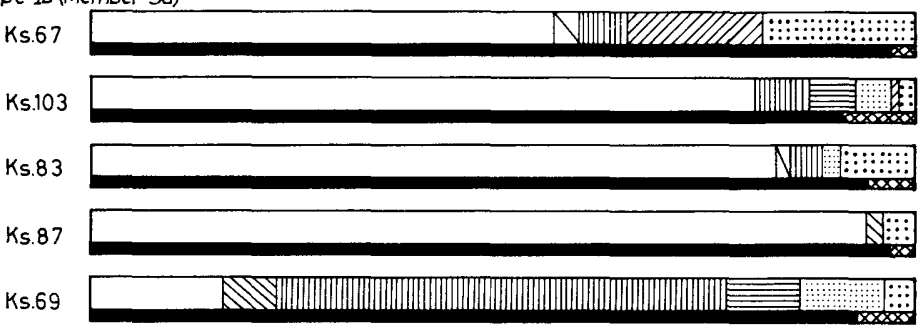

Type Ib (Kanokura Formation)

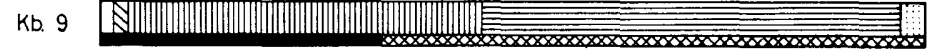

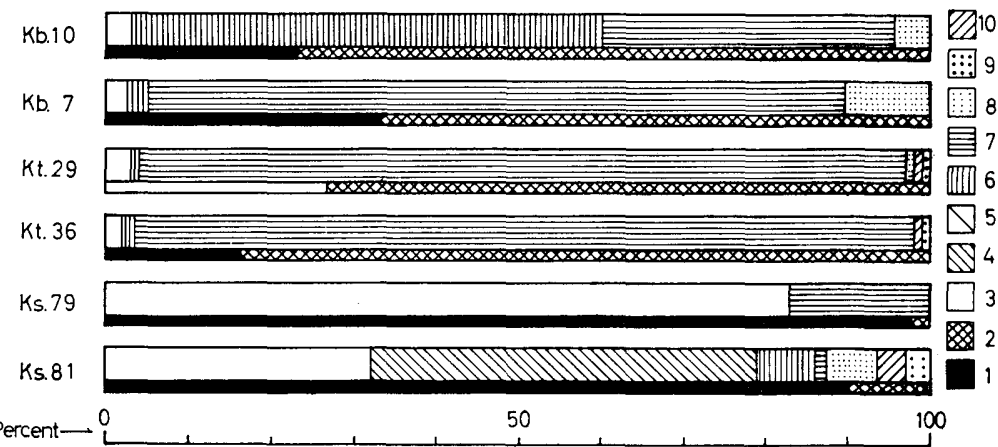

Fig. 12. Heavy mineral assemblage of the Sakamotozawa and Kanokura sandstones.

1. percentage of opaque minerals; 2. percentage of transparent minerals; 3. zircon; 4. garnet; 5. monazite; 6. hornblende; 7. augite; 8 . hypersthene; 9 . biotite; 10 . tourmaline. 


\section{B. Sedimentological remarks}

The sandstone occupies about one fifth of the total thickness of strata in the type section in the surveyed area. Sandstone beds show a remarkable lateral change in thickness. They are apparently thin or thick and sometimes show a lenticular shape, but do not keep a well-traceable, blanket form.

Sandstones are divided into two main types, as shown in Fig. 6 . The type I sandstone is of lithic arenite and shows higher mineralogical maturity (Table 2) than the type II (feldspathic and lithic arenites, Fig. 6). A large amount of opaque minerals and a small amount of relatively stable minerals like zircon and others are contained in the heavy residues of the type I. The total thickness of the sandstone beds is thin. These facts seem to suggest that the type I sandstone deposited slowly and that the source rocks were subject to chemical and mechanical weathering to a considerable extent. That is to say, the source areas were not conspicuously upheaved during the deposition of the sandstone of this type, and were not subject to so remarkable erosion as to supply a great quantity of clastic materials into the depositional basin.

The type II sandstone has a lower mineralogical maturity and worse roundness (Table 1). It is rich in mafic minerals, such as hornblende and augite, except for sandstone of Member Sbl. Their content is as much as 70 per cent of the total heavy mineral content in an extreme example of the IIb sandstone. These features indicate that the erosional activity in the source area became considerably rapid and intense.

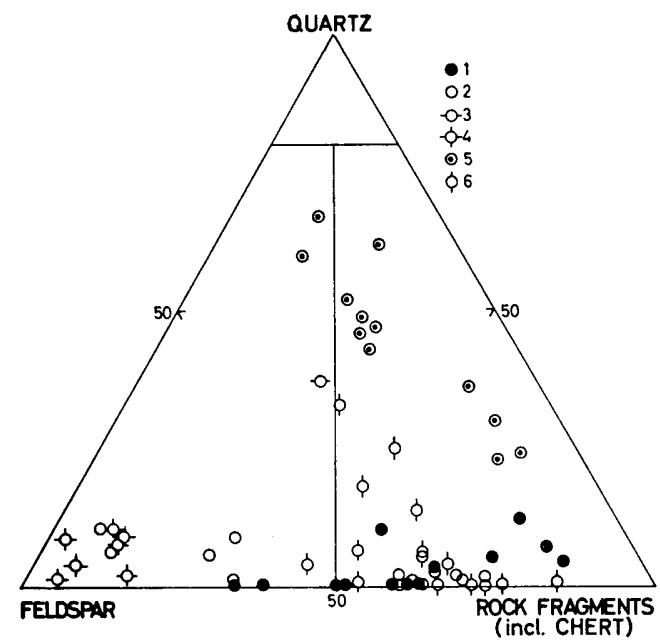

Fig. 13. Comparison of volcanic sandstones [on OKADA's diagram (1968)].

1. Aure greywackes (EDwARDs, 1950, table 1; wacke type), 2. Parry and Tamworth Groups (Crook, 1960, table 2; arenite type), 3. Tyee Formation (DotT, 1964, p. 628), 4. Shimanoshita Member (OKADA and NAKao, 1968, fig. 1; arenite type), 5. Shiiya and Nishiyama Formations (SASAKI and UshiJima, 1966, figs. 6 and 8), 6. Broughton sandstone (RAAM, 1968, table 2). 
The rock fragments contained in both types (I and II) of sandstone are almost similar in composition, consisting mainly of pyroxene andesite, rhyolitic or dacitic volcanic rocks, chert and shale. Accordingly, both types of sandstone must have received their clasts from the provenance composed of intermediate to acid volcanics and sedimentary rocks. The stratigraphic variation in composition and texture of sandstones may indicate the change of activity of erosion and rate of accumulation, but not attributed to a lithological dissimilarity of the source area.

In the petrographic characters of major and minor compositions, the Sakamotozawa and Kanokura sandstones of the type II, are similar to sandstones described by Crook (1960), EdWARds (1950), EdWARD and Glassner (1953), SASAKI and UshiJIma (1966) and OKADA and NAKAo (1968) (see Fig. 13). It is considered that these kinds of sandstone may have accumulated under tectonically unstable environments associated with contemporaneous volcanisms and/or have been derived from volcanic sources close to the depositional site. The unstable characters of the constituents and texture of these kinds of sandstone also suggest that the distance of transportation was rather short.

The Sakamotozawa and Kanokura sandstones show some differences from the Upper Palaeozoic sandstones of several other regions in Japan, which were studied by Kimura (1957), Mizutani (1957), Shiki (1959, 1961) and FUJI (1962) (see Figs. 14 and 15). A majority of the sandstone specimens (59/72) of the Yatsushiro area (FUJII, 1962)) and about a half $(16 / 27)$ of the specimens of the Mugi area (Mizutani, 1957) are of a wacke-type. All specimens (28) of the Tajimi area are also of wacke-type, which have the matrix ranging from 24.1

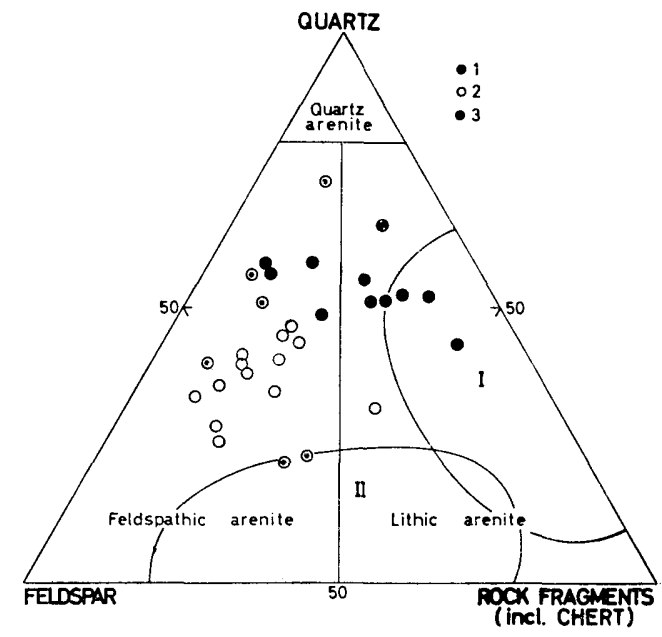

Fig. 14. Comparison of Upper Palaeozoic sandstones in Japan I (on OKADA's diagram).

1. Amatsuki Formation (1 specimen), Yoshio Formation (9 specimens) and Yonaku Formation (3 specimens) (FuJII, 1962), 2. Mugi area (Mizutani, 1957), 3. AsoGokasho district (KIMURA, 1957), 4. and 5. sandstones of the Sakamotozawa and Kanokura Formations. 


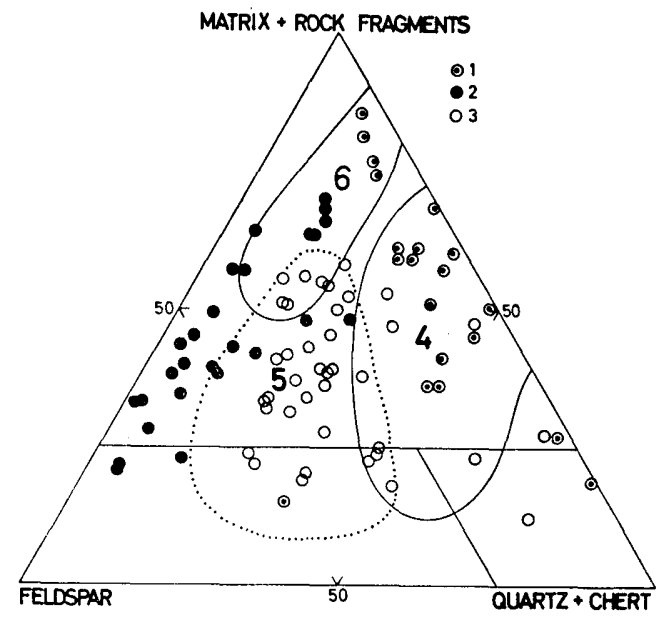

Fig. 15. Comparison of Upper Palaeozoic sandstones in Japan II (on the scheme of DAPPLES et al., 1953)

1. Mugi and Tajimi areas (54 specimens, Mizutani, 1957); 2. Yatsushiro area (59 specimens, FuJIr, 1962); 3. Maizuru area (21 specimens, SHIKI, 1959); 4. Type I sandstones of the Sakamotoza and Kanokura Formation; 5. Type II sandstones of the same formations; 6. AsoGokasho district (38 specimens, KIMURA, 1957).

to 61.2 per cent of the total composition (Mizutani, 1957, p. 41, table 2). Wacketype sandstone also predominates in the Palaeozoic formations of the Chichibu belt in the Aso-Gokasho district of the Kii peninsula (KImURA, 1957, p. 254). On the other hand, the Sakamotozawa and Kanokura sandstones are of arenite-type, having a small amount of matrix. Arenites of the Yatsushiro, Kii and Mugi area, having a relatively low content of rock fragments, show a different composition as compared with those of the Kitakami area as shown in Fig. 15.

It is presumed that source rocks of Upper Palaeozoic sandstones of the Yatsushiro area consist largely of granitic and metamorphic rocks, though the predominant kinds of rocks change from time to time (FUJII, 1962). Arkosic sandstones of the Mugi area (MizUTANI, 1957) and sandstones of the Aso-Gokasho district (KIMURA, 1957) seem to indicate the granitic source.

In the southern Kitakami region, the Usuginu conglomerate which is characterized by pebbles to boulders of granite is widely distributed. Some comments for the geological age and source area have been discussed by authors. ONUKI (1956) mentioned that this conglomerate interfingers with the sediments from the upper Lower Permian to the Upper Permian. IWAI and IshizaKI (1966) considered from the result of the analysis and observation of some sedimentary features that the material of this conglomerate was supplied from some narrow uplifted belts within the sedimentary basin, which were formed during the time of the Middle to Upper Permian. The Sakamotozawa and Kanokura sandstones, however, indicate the volcanic and sedimentary sources, but present no evidence of the granitic source. 
The volcanic rocks, e.g. porphyritic tuff, quartz andesite, keratophyre and schalstein, are predominant in the pre-Permian sequence of the Kesen area (MiNAto et al., 1959a, b and c). Although the amount of the volcanic rocks decreases in the Sakamotozawa Formation, thin beds (under $30 \mathrm{~cm}$. thick) of schalstein and andesitic tuff are intercalated in the basalt member in the Setamai area. On the other hand, schalstein and andesitic agglomerate increase in the Permian sediments of the northern Kitakami region (ONUKI, 1956). Judging from these facts, it is considered that volcanic fragments which characterize the Sakamotozawa and Kanokura sandstones are closely connected with the volcanisms which took place in the Kitakami area during the Middle to Upper Palaeozoic period. In the present state of knowledge, the writer cannot precisely conclude whether the volcanic rock fragments of the Permian sandstones were connected with the contemporaneous volcanisms in the depositional site or not.

From the lithological and sedimentological characters as described above, it is evident that the sandstones of the surveyed area cannot be ascribed to the Molasse-type sediments or to those of the post-orogenic facies and that they are dissimilar to the sediments accumulated on a stable shelf with a cratonic hinterland.

\section{Conclusion}

At the conclusion of the present study the results are summarized as follows :

(1) The limestones of the Sakamotozawa Formation are well bedded and are generally composed of fragmentary and non-fragmentary fossils such as oncolites, dasycladaceae and codiaceae algae, crinoids, fusulines, gastropods and brachiopods. They are petrographically classified into twelve lithologic-types, as listed in p. 340-341. The matrix is mainly micritic.

(2) In the sequence of the Sakamotozawa Limestone ten cyclic units are recognized. A cyclic unit which indicates a serial change of the sedimentary environment begins with the sediments which were formed under an intertidal, lagoonal condition, followed by those of a near-shore environment of open sea, and ends with thin transitional part which is succeeded by the next cyclic unit.

(3) The cyclic pattern of the Sakamotozawa Limestone shows a reversed order as compared with that of a typical cyclic sequence from a transgressive phase to a regressive one in the sediments in more stable areas outside Japan. Such a peculiarity of the cyclic sedimentation may be mainly related to an oscillatory movement caused by a provincial tectonic movement which happened in the geosynclinal period.

(4) The sandstones of the Sakamotozawa and Kanokura Formations occupy only about 20 per cent of the entire thickness and show a remarkable lateral change in facies. They are generally referred to arenite, and divided into four types from a standpoint of the major framework constituents, as is shown in Fig. 6. They differ in composion from the Palaeozoic sandstones which were described by previous authors from several other areas of Japan, as is clearly illustrated in Figs. 14 and 15. 
(5) A serial change of the sandstone type and the mineralogical maturity can be recognized as one follows vertically the succession. It occurs twice in the entire sequence, showing a cyclic change of the erosional activity caused by a major periodic movement of the source area.

(6) From the main composition and the heavy mineral assemblage of sandstone it is presumed that the source areas were composed of the sedimentary rocks and the intermediate and acid volcanic rocks, from andesite to rhyolite. The Devonian and Lower Carboniferous of the south Kitakami region have the so-called "andesite" and "keratophyre", as well as the sedimentary rocks. A part of them may have been elevated and become sources of the sandstones of the Sakamotozawa and Kanokura Formations.

(7) The Sakamotozawa Formation has not the characters of the Molasse nor those of the sediments on a stable continental shelf. It is considered that this formation represents shallow sea sediments deposited on an island shelf. The island itself may have been locally formed within the Chichibu geosyncline in the course of the tectonic development.

\section{References}

Bathurst, R. G. C. (1958): Diagenetic fabrics in some British Dinantian limestones. Liverpool and Manchester Geol. J., 2, (1), 11-36.

(1959): The cavernous structure of some Mississippian stromatactis reef in Lancashire, England. J. Geol., 67, (5), 506-521.

(1967): Depth indicators in sedimentary carbonates. Marine Geol., 5, (5/6), 447-471.

Bisseld, H. J. (1962) : Permian rocks of parts of Nevada, Utah, and Idaho. Geol. Soc. Amer. Bull., 73, (9), 1083-1110.

(1964): Patterns of sedimentation in Pennsylvanian and Permian strata of part of the eastern Great Basin. In symposium on cyclic sedimentation. Kansas Geol. Survey Bull., 169, (1), 43-56.

CARozzi, A. V. (1960): Microscopic sedimentary petrography. Wiley, $485 \mathrm{p}$.

Chilingar, G. V., Bissell, H. J. and Wolf, K. H. (1967) : Diagenesis of carbonate rocks. 127-322, in Chilingar, G. V., Bissell, H. J. and Fairbridge, R. W. (editors): Carbonate rocks, 471 p., Elsevier, Amsterdam.

Cloud, P. E., Jr. (1942): Note on stromatolites. Amer. J. Sci., 240, 363-379.

CRook, K. A. W. (1960)) : Petrology of Parry Group, Upper Devonian-Lower Carboniferous, Tamworth-Nundle district, New South Wales. J. Sediment. Petrol., 30, (4), 538-552.

Dapples, 'E. C., Krumbein, W. C. and Sloss, L. L. (1953) : Petrographic and lithological attributes of sandstones. J. Geol., 61, 291-317.

Dотт, R. H. Jr. (1958): Cyclic patterns in mechanically deposited Pennsylvanian limestones of northeastern Nevada. J. Sediment. Petrol., 28, (1), 3-14. (1964): Wack, graywake and matrix-what approach to immature sandstone classification? Ibid., 34, (3), 625-638.

(1964) : Superimposed rhythmic stratigraphic patterns in mobile belts. Kansas Geol. Surv., Bull., 169, (1), 69-85.

Duff, P. M. C., Hallam, A. and Walton, E. K. (1967): Cyclic sedimentation. Elsevier, $280 \mathrm{p}$.

EDWARDS, A. B. (1950): The petrology of the Miocene sediments of the Aure Trough, Papua. Proc. Roy. Soc. Victoria, 60, 123-148.

and Glaessner, M. F. (1953): Mesozoic and Tertiary sediments from the Wahgi Valley, New Guinea. Ibid., 64, 93-112. 
ENDo, R. (1951): Stratigraphical and palaeontological studies of the later Palaeozoic calcareous algae in Japan I. Trans. Proc. Palaeont. Soc. Japan, N. S., (4), $121-129$.

(1952) : Ibid. II. Ibid., (5), 139-144.

FolK, R. L. (1959): Practical petrographical classification of limestones. Amer. Assoc. Petrol. Geologists, Bull., 43, (1), 1-38.

(1962): Spectral subdivision of limestone types. In Classification of carbonate rocks. Ibid., Mem., 1, 62-84.

and WarD, W. C. (1957): Brazos River Bar: A study in the significance of grain size parameters. J. Sediment. Petrol., 27, (1), 3-26.

FUJII, K. (1962) : Petrography of the Upper Palaeozoic sandstones from the Yatsushiro area, Kyushu. Mem. Fac. Sci. Kyushu Univ., Ser.D, 12, (3), 179-218.

GEORGE, T. N. (1958): Lower Carboniferous palaeogeography of the British Isles. Proc. Yorkshire Geol. Soc., 31, (3), 227-318.

(1960): Lower Carboniferous rocks in County Wexford. Quart. J. Geol. Soc. London, 116, (4), 349-364.

GINSBURG, R. N. (1960) : Ancient analogous of resent stromatolites. 21st Internat., Geol. Congr., Proc., Pt. 22, 26-35.

HaM, W. E. and Pray, L. C. (1962): Modern concepts and classification of carbonate rocks. Amer. Assoc. Petrol. Geologists, Mem., 1, 2-19.

HANZaWA, S. (1938): An aberrant type of the Fusulinidae from the Kitakami Mountainland, northeastern Japan. Proc. Imp. Acad. Tokyo, 14, (7), 255-259.

(1939): Stratigraphical distributions of the genera Pseudoschwagerina and Paraschwagerina in Japan, with descriptions of two new species of Pseudoschwagerina from the Kitakami Mountainland, northeastern Japan. Jap. Jour. Geol. Geogr., 16, (1-2), 65-73.

IWAI, J. and IsHIZAKI, K. (1966) : A preliminary study on the Usuginu type conglomerate-with special reference to the paleogeographical and structural significance. (in Japanese with English abstract). Contrib. Institute Geol. Paleont., Tohoku Univ., (62), 35-53.

Johnson, H. J. (1946): Lime-secreting algae from the Pennsylvanian and Permian of Kansas. Geol. Soc. Amer., Bull., 57, (12), 1087-1120.

(1961): Limestone-building algae and algal limestones. Johnson, Boulder, Colo., $297 \mathrm{p}$.

KANMERA, K. and Mikami, T. (1965a): Succession and sedimentary features of the Lower Permian Sakamotozawa Formation. Mem. Fac. Sci., Kyushu Univ., Ser. D., 16, (3), 265-274.

(1965b): Fusuline zonation of the Lower Permian Sakamotozawa Series. Ibid., 275-320.

KANo, H. (1955) : Preliminary notes on tectonic relations between the granitic rocks and their country rocks in the Kitakami-central zone (II). (in Japanese with English abstract). J. Geol. Soc. Japan, 61, (714), 124-139.

Kimura, T. (1957): The geologic structure and the sedimentary facies of the Chichibu Group in the eastern Kii Peninsula; a contribution to the geotectonic study of southwest Japan. Sci. Paper, Coll. Gen. Educ. Univ. Tokyo, 7, 243-272.

KoNishI, K. (1959): Notes on some Japanese Permian and Cretaceous algae and their stratigraphic setting. J. Fac. Sci., Univ. Tokyo, sec.II, 11, (4) , 441-456.

LoGAN, B. W., ReZAK, R. and GINSBURG, R. N. (1964): Classification and environmental significance of algal stromatolites. J. Geol., 72, (1), 68-83.

LucIa, F. J. (1962) : Diagenesis of a crinoidal sediment. J. Sediment. Petrol., 32, (4), 848-865.

MATTER, A. (1967): Tidal flat deposits in the Ordovician of western Maryland. $J$. Sediment. Petrol., 37, (2), 601-609.

Mawson, D. (1929): Some south Australian algal limestones in process of formation. Quart. J. Geol. Soc., 85, (4), 613-623.

MCMASTER, R. L. and CoNover, J. T. (1966): Recent algal stromatolites from the 
Canary Islands. J. Geol., 74, (5), 647-652.

Mikami, T. (1965) : The type Sakamotozawa Formation. (in Japanese with English abstract). J. Geol. Soc. Japan, 71, (841), 475-493.

Minato, M. (1966): Stratigraphie des Palaeozoikum des Kitakami-Gebirges und Abe-Orogenese in Japan. (in Japanese with Germany abstract). Professor S. Matsushita Mem. Volume, 143-159.

Minato, M. et al. (1954): Zur biostratigraphie der permischen Formation des Setamai-Gelandes im Sud-Kitakami Gebirge. (in Japanese with Germany abstract). J. Geol. Soc. Japan, 60, (708), 378-387.

(1959a): On the volcanic rocks in the Japanese Palaeozoic, 1st Rep., Gotlandian and Devonian. (in Japanese with English abstract). Ibid., 65, (761), $71-79$.

(1959b): Ibid., 2nd Rep., Carboniferous. (in Japanese with English abstract) . Ibid., (762), 165-170.

(1959c): Ibid., 3rd Rep., Permian. (in Japanese with English abstract). Ibid., (763), 222-226.

Mizutani, S. (1957): Permian sandstones in the Mugi area, Gifu prefecture, Japan. J. Earth Sci., Nagoya Univ., 5, (2), 135-151.

Moore, R. C. (1964): Paleoecological aspects of Kansas Pennsylvanian and Permian cyclothems. 287-380, in MERRIAN, D. F. (editor), Symposium on cyclic sedimentation. K. G. S. Bull. $169,1,380$ p., Kansas.

Morikawa, R. (1953): Fusulinids from the Kitakami mountainland. (in Japanese with English abstract). J. Geol. Soc. Japan, 61, (691), 149-159.

Nakamura, K. (1959): Some Lower Permian Sakamotozawa brachiopods. J. Fac. Sci., Hokkaido Univ., Ser. IV, Geol. \& Mineral., 10, 199-207.

(1960): Dictyoclostus derived from the Middle Permian Kanokura series and the Lower Permian Sakamotozawa series of the Kitakami mountains, Japan. Ibid., 10, 495-511.

OKADA, H. (1966) : Non-greywacke "Turbidites" sandstones in the Welsh geosyncline. Sedimentology, 7, (3), 221-232. (1968): Classification and nomenclature of sandstones. (in Japanese with English abstract). J. Geol. Soc. Japan, 74 ,(7), 371-384.

, and NAKAO, S. (1968): Plagioclase arenite in Lower Cretaceous flysch in the Furano area, Hokkaido. (in Japanese). Ibid., 74, (8), 451-452.

ONuKI, Y. (1956): Geology of Kitakami. (in Japanese). Iwate Prefecture, 1-98.

Perkins, R. D. (1963) : Petrology of the Jeffersonville Limestone (Middle Devonian) of Southeastern Indiana. Bull. Geol. Soc. Amer., 74, 1335-1354.

Pettijohn, F. J. (1957) : Sedimentary rocks, second edition. Happer and Brothers, $718 \mathrm{p}$.

Powers, M. C. (1953) : A new roundness scale for sedimentary particles. J. Sediment. Petrol., 23, 117-119.

RAAM, A. (1968): Petrology and diagenesis of Broughton sandstone (Permian) Kiama district, New South Wales. J. Sediment. Petrol., 38, (2), 319-331.

SASAKI, K. and UshiJIMA, N. (1966) : Sedimentation of graded sandstones in Shiiya and Nishiyama formations, Higashiyama oil belt, Niigata Prefecture. (in Japanese with English abstract). J. Japan Assoc. Mineralogists, Petrologists and Petroleum Geologists, 56, (4), 161-182.

SHIKI, T. (1959): Studies on sandstones in the Maizuru zone, southwest Japan I. Importance of some relations between mineral composition and grain size. Mem. Coll. Sci., Kyoto Univ., Ser. B, 25, (4), 239-246.

(1961): Studies on sandstones in the Maizuru zone, southwest Japan II. Graded bedding and mineral compositions of the Maizuru Group. Ibid., 27, (3), 294-308.

Toriyama, R. (1952): Permian fusulinids from the Kitakami Mountainland, Northeast Japan. Mem. Fac. Sci., Kyushu Univ., [D], 3, (3), 127-256.

Wolf, K. H. (1960) : Simplified limestone classification. Amer. Assoc. Petrol. Geol- 
ogists, Bull., 44, (8), 1414-1416.

(1965a): Petrogenesis and palaeoenvironment of Devonian algal limestones of New South Wales. Sedimentology, 4, (2), 113-178.

(1965b) : "Grain-diminution" of algal colonies to micrite. J. Sediment. Petrol., 35, (2), 420-427.

(1965c): Gradational sedimentary products of calcareous algae. Sedimentology, 5, (1), 1-37.

(1965d): Littoral environment indicated by open-space structures in algal limestone. Palaeogeography, Palaeoclimatology, Palaeoecology, 1, 183-223.

Woop, A. (1941): "Algal dust" and finer-grained varieties of Carboniferous limestone. Geol. Mag., 78, (3), 192-200.

YAMADA, Y. (1959): On the unconformity of the post-Nagaiwa Pre Sakamotozawa epoch in the Hikoroichi district. (in Japanese with English abstract). J. Geol. Soc. Japan, 65, (771), 713-724. 
Takahiko MıKAMI

A sedimentological Study of the Lower Permian Sakamotozawa Formation

Plates $46 \sim 52$ 
Plate 46 


\section{Explanation of Plate 46}

Figs. 1 and 2: Algal biosparite. 1: Middle part of the cyclic unit 4. Nishiyama quarry, Ks. 218. 2: Lowest part of the cyclic unit 1. Endozawa, Ks. $157 . \times 6$.

Fig. 3: Algal pellet biomicrite. Middle part of Member Sc. Shiratorizawa, Ks. $145 . \times 6$.

Figs. 4 and 5: Algal biomicrite. 4: Middle part of the cyclic unit 2. Tashiroyama, Ks.11. 5: Middle part of the cyclic unit 4. Nishiyama quarry, Ks. $199 . \times 6$.

Figs. 6 and 7: Algal pseudoöid biosparrudite. 6: Lower part of the cyclic unit 1. Northern part of the Higashiyama quarry, Ks. 61. 7: Lower part of the cyclic unit 1 . Sakamotozawa, Ks. 126-1. $\times 6$.

Fig. 8. Algal pseudoöid biosparite. Lower part of the cyclic unit 1. Sakamotozawa, Ks. 126-2. $\times 6$. 

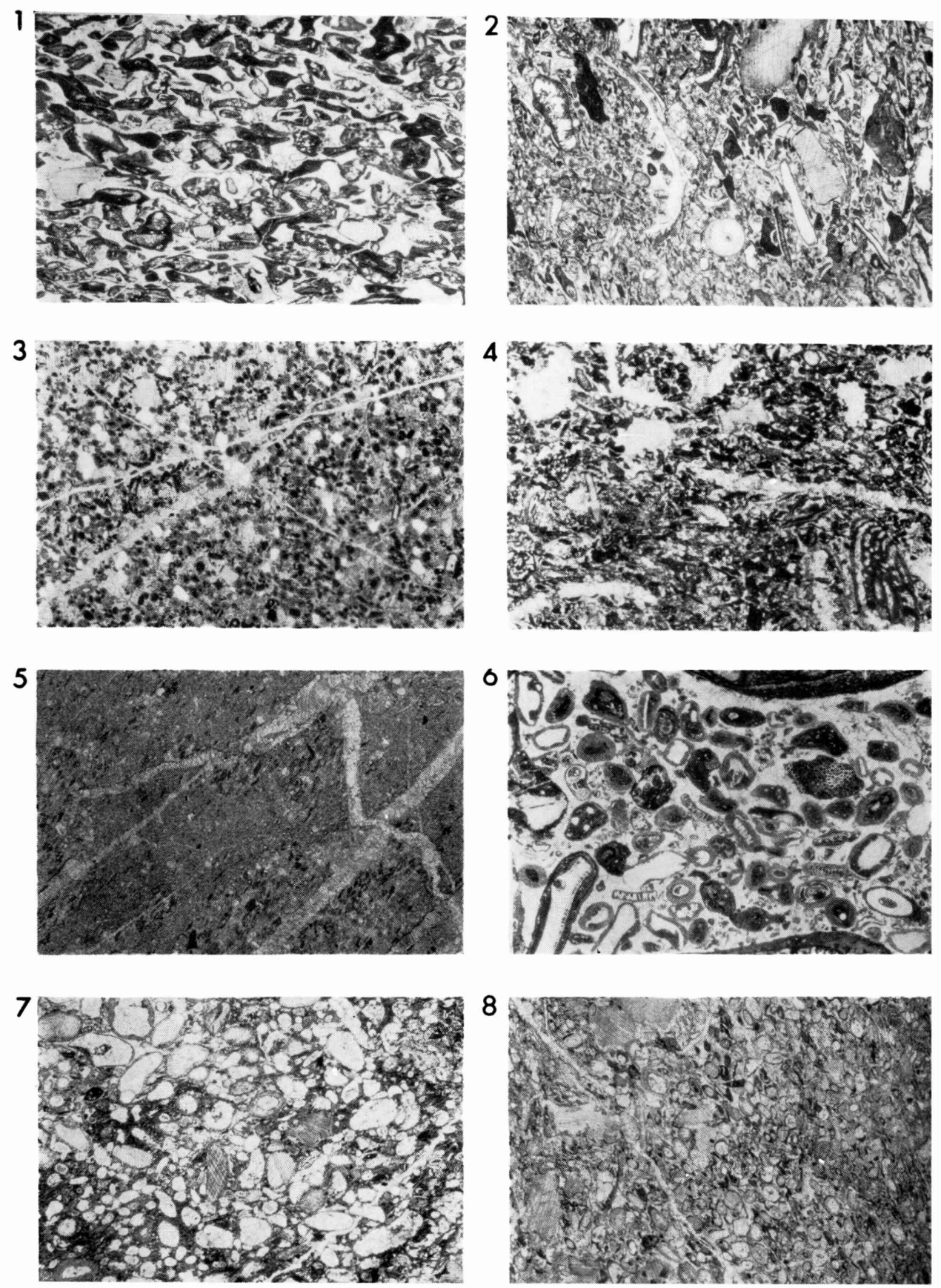

T. Mikami: Sedimentological study of the Sakamotozawa Formation. 
Plate 47 


\section{Explanation of Plate 47}

Fig. 1: Algal biomicrudite. Dasycladacean algae are abundant. The matrix is lime-mud which was delivered by mechanical disintegration of algal filaments. Middle part of the cyclic unit 7. Higashiyama quarry, Ks. 151. $\times 6$.

Fig. 2: Gastropod biomicrudite. A gastropod shell is enclosed by a dense micritic crust, which is of an algal origin, but secondarily changed to pseudomicrite. The inside of the shell is filled with lime-mud which is probably of disintegrated algal matter (allomicrite of WoLF). Middle part of the cyclic unit 7. Shiratorizawa, Ks. 227. $\times 6$.

Fig. 3: Oncolite. Lower part of cyclic unit 1. Nishiyama quarry, Ks. 1001. $\times 6$.

Fig. 4: Feldspar crinoid biomicrudite. Detrital grains are mostly feldspar and rarely quartz and volcanic rock fragments. This type of crinoidal limestone represents a part of the marginal facies of crinoidal biopseudosparrudite which typically occurs in the cyclic unit 6 at the Nagaiwa mine. Member Sb3, Sakamotozawa, Ks. 120. $\times 6$.

Figs. 5 and 6: Algal biomicrite. 5: Upper part of the cyclic unit 4. Nishiyama quarry, Ks. 48. 6: Upper part of the cyclic unit 3. Tashiroyama, Ks. 9. $\times 6$. 

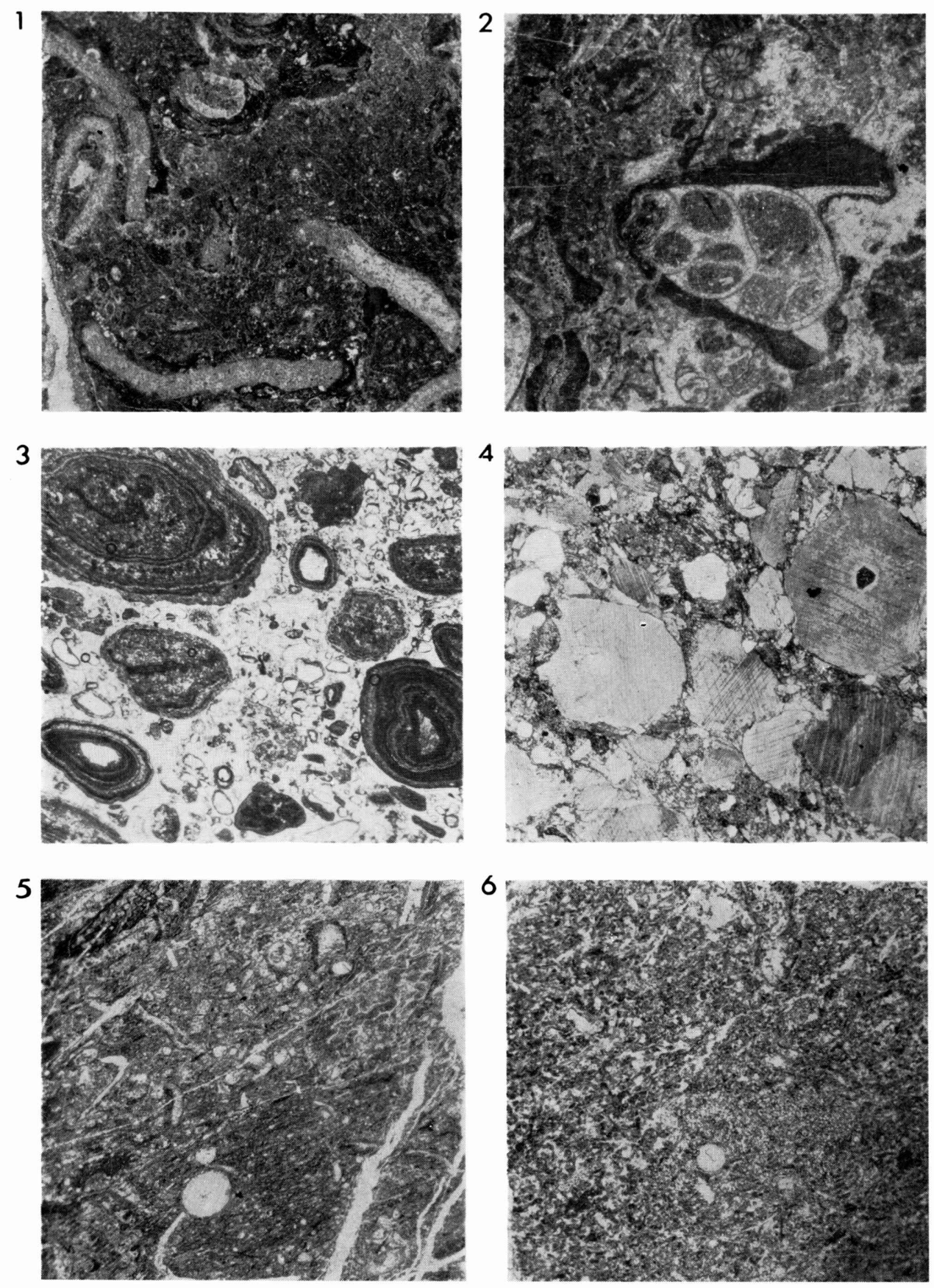

T. Mikami: Sedimentological study of the Sakamotozawa Formation. 
Plate 48 


\section{Explanation of Plate 48}

Figs. 1 and 2: Fusuline biosparrudite. Middle part of Member Sd. Shiratorizawa (1: Ks. 42-1, 2: K.s. 39). $\times 6$.

Figs. 3 and 4: Algal biosparrudite. 3: Upper part of the cyclic unit 5 . Tashiroyama, Ks. 17. 4: Middle part of the cyclic unit 3. Nishiyama quarry, Ks. $166 . \times 6$.

Fig. 5: Algal biomicrudite. This limestone is composed mainly of fragmentary oncolites and dasycladacean algae. Upper part of the cyclic unit 1 . Nishiyama quarry, Ks. $194 . \times 6$.

Fig. 6: Fusuline biomicrudite. Upper part of Member Sd. Shiratorizawa, Ks. $42-2 . \times 6$. 

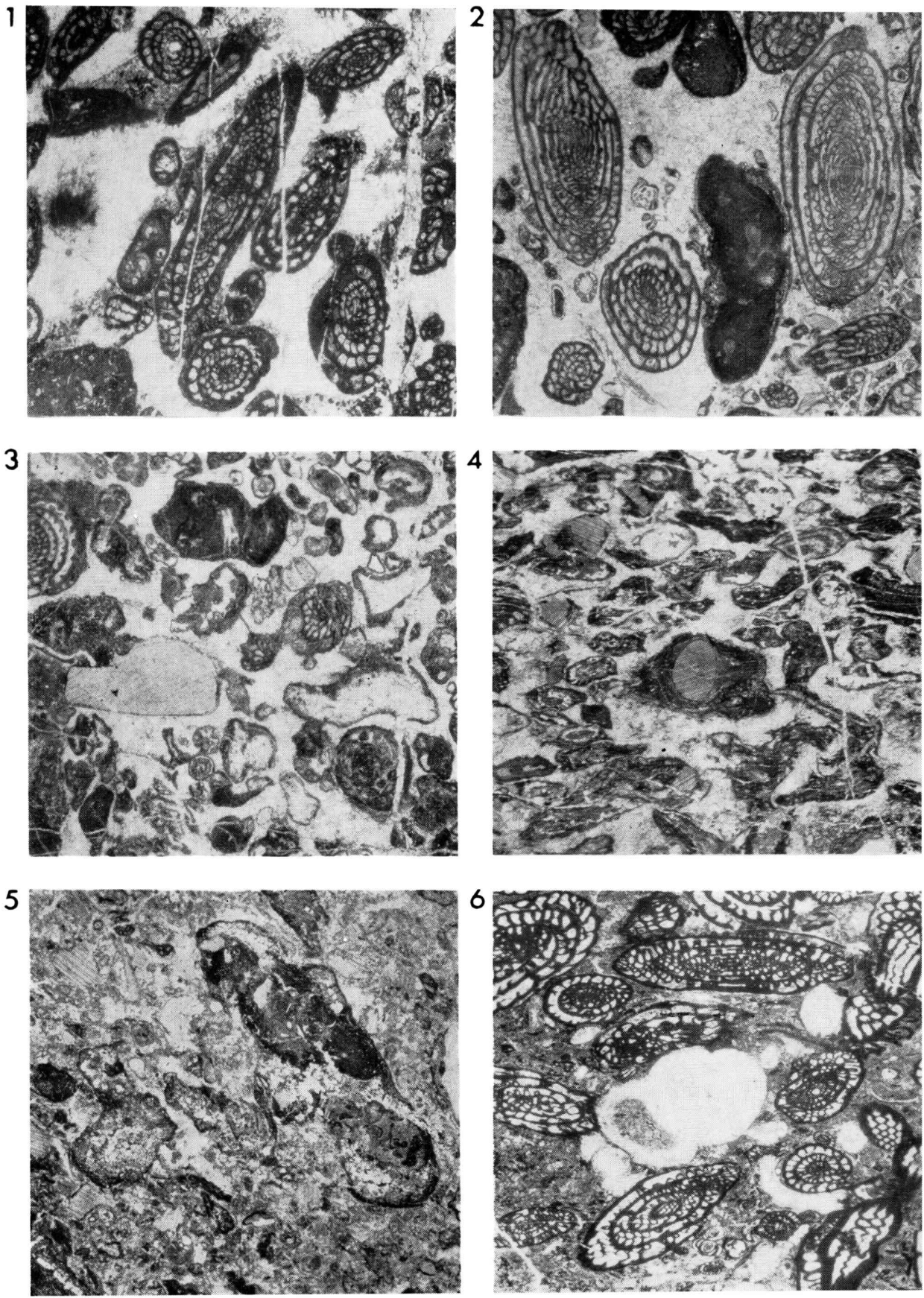

T. Mikami: Sedimentological study of the Sakamotozawa Formation. 
Plate 49 


\section{Explanation of Plate 49}

Figs. 1, 2 and 4: Algal biomicrudite. 1: Authigenic overgrowth of quartz around the clastic quartz is seen in the lower part of the figure. Thalli of Mizzia velevitana are largely recrystallized by grain-growth of calcite and show a ghost structure. Middle part of the cyclic unit 8 . Higashiyama quarry, Ks. 1003. $\times 6$. 2: Middle part of the cyclic unit 1. Sakamotozawa, Ks. 1004. $\times 6$. 4: Middle part of the cyclic unit 8 . Higashiyama quarry, Ks. $1005 . \times 6$.

Fig. 3: Gastropod biomicrudite. Secondary quartz occurs at the center of a gastropod chamber. Middle part of the cyclic unit 8. Higashiyama quarry, Ks. 153. $\times 6$. 

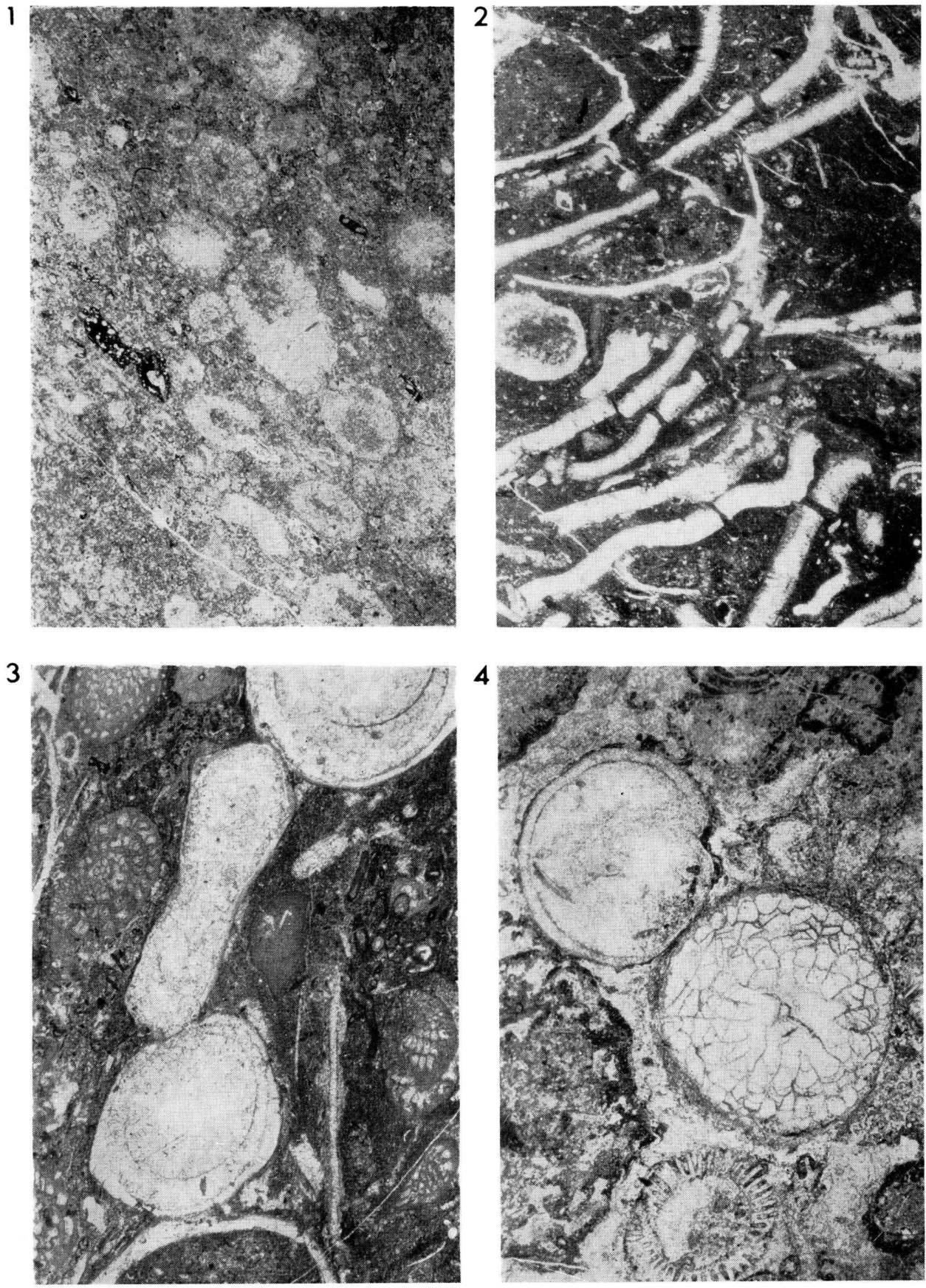

T. Mikami: Sedimentological study of the Sakamotozawa Formation. 
Plate 50 


\section{Explanation of Plate 50}

Figs. 1, 2 and 3: Oncolite. 1 and 2: Lower part of the cyclic unit 1 . Nishiyama quarry, Ks.1001. $\times 10$. 3: Middle part of the cyclic unit 2 . Tashiroyama, Ks. $1006 . \times 6$.

Fig. 3: Crinoidal biomicrudite. Member Sb3. Higashiyama quarry, Ks. 1002. $\times 6$. 

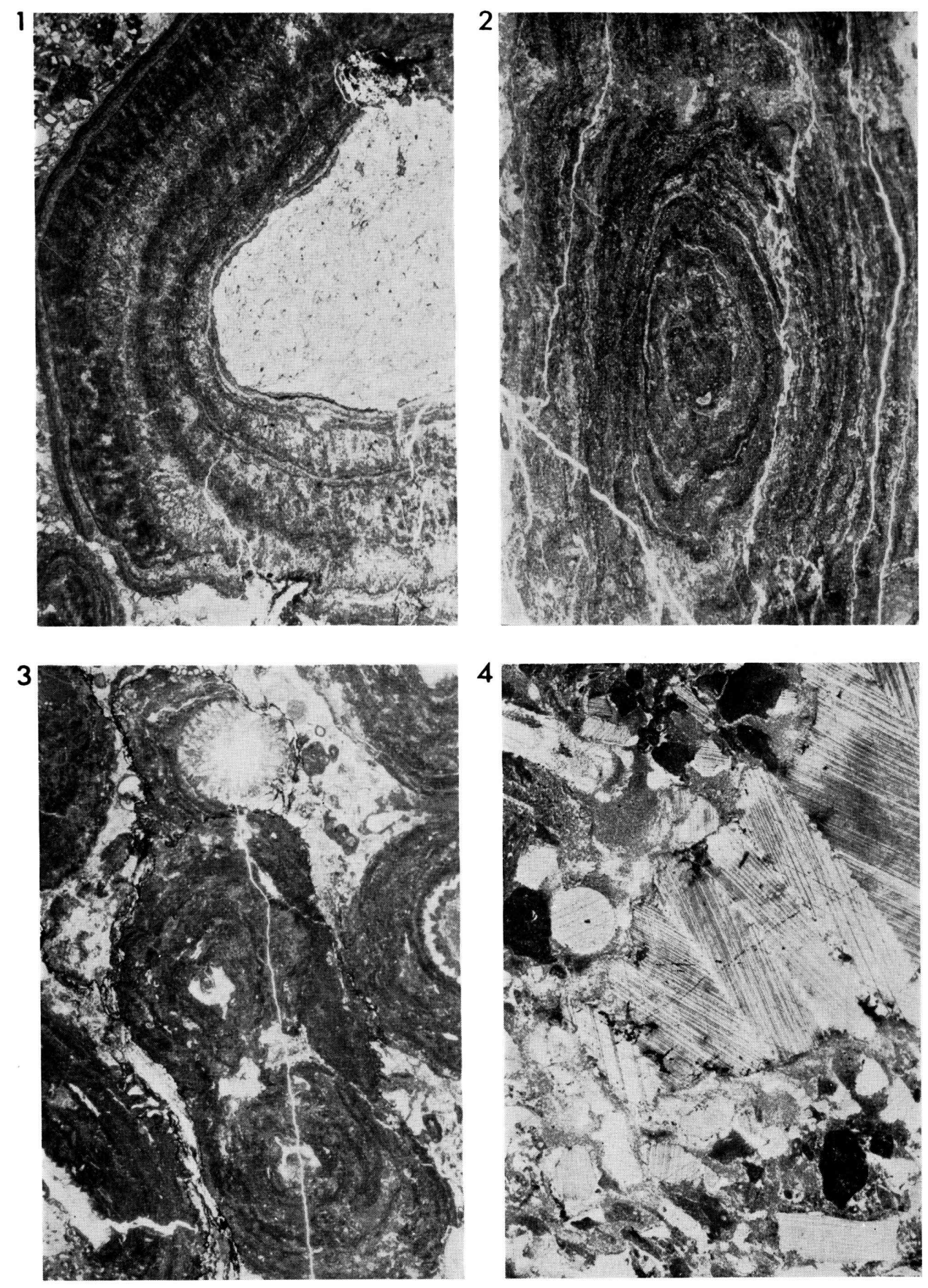

T. Mikami: Sedimentological study of the Sakamotozawa Formation. 


\section{Plate 51}




\section{Explanation of Plate 51}

Figs. 1-3: Lithic arenite (Type Ia). Lower part of Member Sa. Nagaiwa (1: Ks. 86-1, 2: Ks. 108-2, 3: Ks. 87). ×10.

Figs. 4, 5 and 7: Feldspathic arenite (Type IIa). 4 and 5: Middle part of Member Sa. Sakamotozawa (4: Ks. 72, 5: Ks. 70-2) ; 7: Member Sb1. Sakamotozawa. Ks. 77-1. $\times 10$.

Fig. 6: Lithic arenite (Type $\mathrm{Ib})$. Lower part of Member Sd. Higashiyama quarry. Ks. 67-2. $\times 10$.

Fig. 8: Lithic arenite (Type IIb). Kacchizawa sandstone Member. Kacchizawa. Kt. 35-2. $\times 10$. 

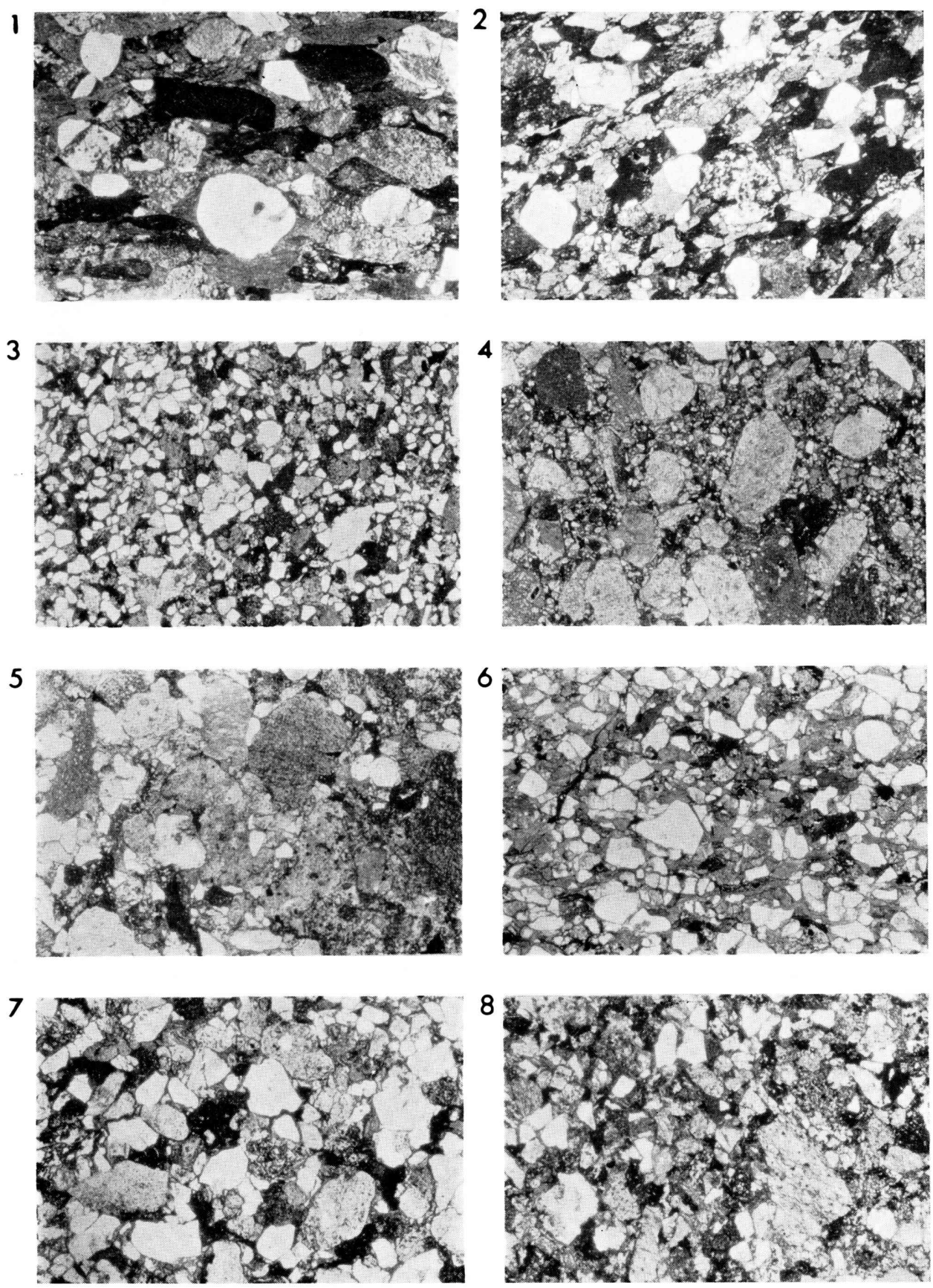

T. Mikami: Sedimentological study of the Sakamotozawa Formation. 
Plate 52 


\section{Explanation of Plate 52}

Figs. 1 and 2: Conglomerate of the basal part of Member Sc. Tashiroyama (1: Ks. 106, 2: Ks. 74-2). × 10 .

Fig. 3: Lithic arenite (Type Ib). Lower part of Member Sd. Nagaiwa. Ks. 69-2. $\times 10$.

Figs. 4 and 5: Lithic arenite (Type IIb). Member Ka. Nagaiwa (4: Ks. 79, 5: Ks. 81-2). $\times 10$.

Fig. 6: Feldspathic arenite (Type IIa). Member Sb1. Sakamotozawa. Ks. 77-1. $\times 10$. 

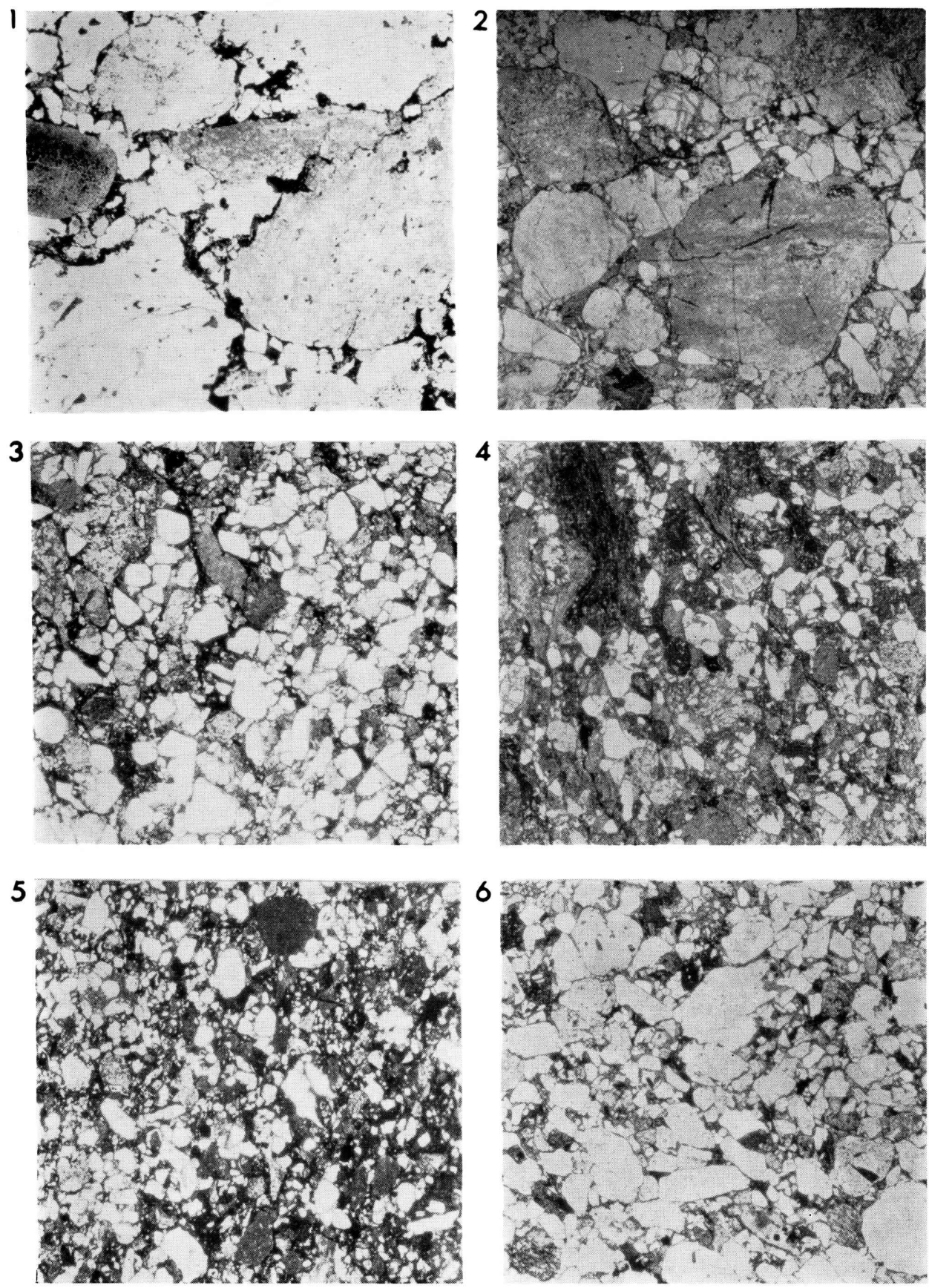

T. Mikami: Sedimentological study of the Sakamotozawa Formation. 